\title{
Functional intercalated nanocomposites with chitosan-glutathione-glycylsarcosine and layered double hydroxides for topical ocular drug delivery
}

This article was published in the following Dove Press journal: International Journal of Nanomedicine

\author{
Tingting $X u^{1,2, *}$ \\ Xiaoyue $\mathrm{Xu}{ }^{1, *}$ \\ Yan Gu' \\ Lei Fang ${ }^{3}$ \\ Feng $\mathrm{CaO}^{\prime}$
}

'School of Pharmacy, China Pharmaceutical University, ${ }^{2}$ Nanjing Chia Tai Tian Qing Pharmaceutical Co., Ltd, ${ }^{3}$ Jiangsu Province Hi-Tech Key Laboratory for Bio-Medical Research and School of Chemistry and Chemical Engineering, Southeast University, Nanjing, China

*These authors contributed equally to this work
Correspondence: Feng Cao

School of Pharmacy, China

Pharmaceutical University, 24 Tongjia

Xiang, Nanjing, 210009, China

Tel +86258327 I092

Email cpufengc@gmail.com

Lei Fang

Jiangsu Province Hi-Tech Key Laboratory

for Bio-Medical Research, School of

Chemistry and Chemical Engineering,

Southeast University, Nanjing 21 I I89,

China

Tel +86 255209 I I39

Email lei.fang@seu.edu.cn
Background: To enhance ocular bioavailability, the traditional strategies have focused on prolonging precorneal retention and improving corneal permeability by nano-carriers with positive charge, thiolated polymer, absorption enhancer and so on. Glycylsarcosine (GS) as an active target ligand of the peptide tranpsporter-1 (PepT-1), could specific interact with the PepT-1 on the cornea and guide the nanoparticles to the treating site.

Purpose: The objective of the study was to explore the active targeting intercalated nanocomposites based on chitosan-glutathione-glycylsarcosine (CG-GS) and layered double hydroxides $(\mathrm{LDH})$ as novel carriers for the treatment of mid-posterior diseases.

Materials and methods: CG-GS-LDH intercalated nanocomposites were prepared by the coprecipitation hydrothermal method. In vivo precorneal retention study, ex vivo fluorescence images, in vivo experiment for distribution and irritation were studied in rabbits. The cytotoxicity and cellular uptake were studied in human corneal epithelial primary cells (HCEpiC).

Results: CG-GS-LDH nanocomposites were prepared successfully and characterized by FTIR and XRD. Experiments with rabbits showed longer precorneal retention and higher distribution of fluorescence probe/model drug. In vitro cytological study, CG-GS-LDH nanocomposites exhibited enhanced cellular uptake compared to pure drug solution. Furthermore, the investigation of cellular uptake mechanisms demonstrated that both the active transport by PepT-1 and clathrin-mediated endocytosis were involved in the internalization of CG-GS-LDH intercalated nanocomposites. An ocular irritation study and a cytotoxicity test indicated that these nanocomposites produced no significant irritant effects.

Conclusions: The active targeting intercalated nanocomposites could have great potential for topical ocular drug delivery due to the capacity for prolonging the retention on the ocular surface, enhancing the drug permeability through the cornea, and efficiently delivering the drug to the targeted site.

Keywords: active targeting, intercalated nanocomposites, peptide transporter-1, layered double hydroxides, glycylsarcosine

\section{Introduction}

Over the past few years, several novel strategies have been developed for delivering drug molecules to the ocular tissues, such as topical, episcleral, subconjunctival, intravitreal, intracameral and intrastromal routes. ${ }^{1-5}$ However, topical administration remains the most preferred route of ocular drug delivery, because it is noninvasive, painless and convenient. ${ }^{6}$ Topically applied drug/formulation may not only reach anterior tissues but also reach back-of-the-eye tissues. ${ }^{7}$ Effective topical drug delivery poses a major challenge due to the presence of various elimination mechanisms and physiological 
barriers that result in low ocular bioavailability. ${ }^{8-10}$ Increasing the retention time in the precorneal area and improving the permeability across ocular tissues of drugs are two major key aspects to enhance ocular bioavailability. ${ }^{1}$ Ban et al developed positively charged chitosan (CTS)-coated solid lipid nanoparticles with high ocular bioavailability, which was ascribed to the electrostatic interaction between the positively charged nanoparticles and the negatively charged ocular surface. ${ }^{11}$ Furthermore, CTS derivatives, especially thiolated CTS, with good mucoadhesivity and enhanced trans-cornea drug penetration have been widely used in topical ocular drug delivery. ${ }^{12} \mathrm{Up}$ to now, no previous work has been reported to enhance corneal permeability by ocular influx transporters with nanoparticles.

Several influx transporters may influence drug bioavailability, which present not only in the intestine but also in the ocular tissues of cornea, conjunctiva, retina and blood-ocular barriers. One of the essential influx transporters is peptide transporter, especially peptide transport-1 (PepT-1) which has a good affinity for many diverse peptide and peptidomimetic substrates. ${ }^{13}$ For instance, Majumdar et al synthesized a series of dipeptide conjugated prodrugs of ganciclovir (GCV) for targeting peptide transporter expressed on the rabbit corneal membrane, which enhanced corneal permeability of GCV by almost seven- to eightfold. ${ }^{14}$ Aqueous pirenoxine sodium (PRN) eye drops are commercially used to inhibit the development of cataract, which suffer from low ocular bioavailability. Layered double hydroxides (LDH) can be efficient ocular delivery vehicles for a series of active compounds, such as diclofenac sodium, phacolysin and brimonidine. ${ }^{15-17}$ Based on the evidence that PepT-1 has been identified in the corneal epithelium of humans, we have recently reported an organic-inorganic intercalated nanocomposite of PRN loaded CTS-glutathione-valine-valine layered double hydroxides (CG-VV-PRN-LDH) for topical ocular drug delivery. ${ }^{18}$ The multifunctional nanocomposites with target ligand of dipeptide VV have been demonstrated with active targeting of PepT-1 in animals and at the cellular level. ${ }^{19,20}$ These intercalated nanocomposites with a synergistic effect between the organic and inorganic materials have received more and more attention in recent years..$^{21-23}$

Glycylsarcosine (GS) is one of the best known reference substrates of PepT-1 and commonly used as an inhibitor in the study of transport mechanism of PepT-1. ${ }^{24-26} \mathrm{GS}$, as an active target PepT-1 ligand, was conjugated with thiolated CTS hybrid LDH to form a multifunctional nanocomposite. We proposed that specific recognition between GS and PepT-1 might significantly enhance corneal permeation for topical ocular drug delivery. To our present knowledge, systematic evaluation of GS as an active target for ligand interactions with PepT-1 has not been reported before.

In this study, a new CTS derivative of CTS-glutathioneglycylsarcosine (CG-GS) was synthesized and characterized. Using coprecipitation method, CG-GS-PRN-LDH nanocomposites were prepared and loaded with PRN as a model drug. The physicochemical characterization, in vitro release, in vivo precorneal residence and ocular tissue distribution of this formulation were evaluated on rabbits. Furthermore, the cytotoxicity, cellular uptake and transport mechanism of CG-GS-PRN-LDH nanocomposites were investigated with human corneal epithelial primary cells.

\section{Materials and methods}

\section{Materials, cells and animals}

PRN was purchased from Chengdu Sino-Strong Pharmaceutical Co., Ltd. ( $\geq 98 \%$; batch number: 150501, Sichuan, China). CTS ( $\mathrm{M}_{\mathrm{w}} 25 \mathrm{kDa}$, degree of deacetylation $\geq 90 \%$ ) was bought from Xingcheng Bio-products Co., Ltd. (Jiangsu, China). L-glutathione reduced form (GSH), $N$-hydroxysuccinimide (NHS), 1-ethyl-3-(3dimethylaminopropyl) carbodiimide hydrochloride (EDC), 3-(4,5-dimethylthiazol-2-yl)-2,5-diphenyltetrazolium bromide (MTT), chlorpromazine hydrochloride, nystatin, genistein and amiloride were all obtained from Aladdin Reagent Database Inc. (Shanghai, China). 5,5'-Dithiobis(2-nitrobenzoic acid) was supplied by Sigma-Aldrich Co. (St Louis, MO, USA). GS, Fmoc $N$-hydroxysuccinimide ester (Fmoc-OSu) and fluorescein isothiocyanate (FITC), Isomer I were purchased from TCI chemicals Co., Ltd. (Shanghai, China). All other chemicals were of chromatographic or analytical grades.

Human corneal epithelial primary cells (HCEpiC) were purchased from American Type Culture Collection (Rockville, DS, USA, Cat No: CRL-6510) and maintained in a humidified incubator at $37^{\circ} \mathrm{C}\left(95 \%\right.$ air and $\left.5 \% \mathrm{CO}_{2}\right)$. For maintenance, the cells were cultivated in the corneal epithelial cell serum-free medium (ScienCell Research Laboratories, Carlsbad, CA, USA) supplemented with 1\% corneal epithelial cell growth supplement and $1 \%$ penicillin/ streptomycin solution.

Male New Zealand albino rabbits weighing 2-3 kg were provided by the Qinglongshan farms in Jiangning District of Nanjing. The animals were housed in standard cages in a light-controlled room at $19^{\circ} \mathrm{C} \pm 1{ }^{\circ} \mathrm{C}$ and at $50 \% \pm 5 \%$ relative humidity and were fed a standard pellet diet and water ad libitum. All animal study protocols complied with the guidelines set by the National Institute of Health Guide for 
the Care and Use of Laboratory Animals, and the study was approved by the Animal Ethical Experimentation Committee of China Pharmaceutical University.

\section{Synthesis and characterization of CG-GS Synthesis of CG-GS}

As shown in Scheme 1, CG-GS was synthesized via the intermediate of CTS-Fmoc-glycylsarcosine (CTS-Fmoc-GS) followed by deprotection and then grafted with GSH. The synthesis of Fmoc-GS was performed as follows: GS $(1.0 \mathrm{~g}, 6.84 \mathrm{mmol})$ was dissolved in $15 \mathrm{~mL}$ of dioxane and $10 \mathrm{~mL}$ of purified water, treated with anhydrous sodium bicarbonate $(1.15 \mathrm{~g}, 13.68 \mathrm{mmol})$ and stirred to form a clear solution at room temperature. Fmoc-OSu (2.77 g, $8.21 \mathrm{mmol}$ ) in $10 \mathrm{~mL}$ of dioxane was gradually added to the mixed solution at ice temperature and stirred for $20 \mathrm{~min}$, and was monitored by thin layer chromatography until the completion of reaction. Then the solvent was removed under reduced pressure followed by adjusting to $\mathrm{pH}$ 5.0. The reaction mixture was extracted with ethyl acetate. After removal of the solvent, the residue was purified by silica gel chromatography with the eluent of dichloromethane and methanol (70:1-10:1) to get oil product. The oil compound was dissolved in dichloromethane $(15 \mathrm{~mL})$ and crystallized with petroleum ether $(150 \mathrm{~mL})$ at room temperature. The solid precipitation was filtered to get the target product as white solid $(2.27 \mathrm{~g})$. Yield was $90.0 \%$. Electrospray ioniztion mass spectrometry: $\mathrm{m} / \mathrm{z}[\mathrm{M}-\mathrm{H}]^{-}=367.15$. Proton nuclear magnetic resonance ( ${ }^{1} \mathrm{H}$ NMR) (300 MHz, DMSO) $\delta 13.08-12.33(\mathrm{~m}$, $1 \mathrm{H}), \delta$ 7.96-7.83 (m, 2H), $\delta 7.78-7.58(\mathrm{~m}, 2 \mathrm{H}), \delta$ 7.56-7.16 $(\mathrm{m}, 5 \mathrm{H}), \delta 4.33-4.18(\mathrm{~m}, 3 \mathrm{H}), \delta 4.15-3.97(\mathrm{~m}, 2 \mathrm{H}), \delta$ 3.94-3.75 (m, 2H), $\delta 3.06-2.79(\mathrm{~m}, 3 \mathrm{H})$.

CTS-Fmoc-GS was synthesized by amide reaction between carboxylic acid groups of Fmoc-GS and amine groups of CTS. ${ }^{19}$ Briefly, CTS $(0.6 \mathrm{~g})$ was hydrated in $3 \mathrm{~mL}$ of $1 \mathrm{M}$ $\mathrm{HCl}$ and then dissolved in $35 \mathrm{~mL}$ of distilled water. The $\mathrm{pH}$ of the solution was adjusted to 5.0 with $1 \mathrm{M} \mathrm{NaOH}$. An aqueous solution of Fmoc-GS was prepared by dissolving Fmoc-GS and EDC in $10 \mathrm{~mL}$ of DMSO at a molar ratio of $1 / 4$ and stirred for $15 \mathrm{~min}$. Then EDC and NHS with the same mole ratio in $5 \mathrm{~mL}$ of DMSO were added to the above mixture solution. Then the solution was added drop wise to CTS solution and adjusted to $\mathrm{pH} 5.0$ with $0.1 \mathrm{M} \mathrm{NaOH}$ again. The mixture solution was stirred at room temperature for $24 \mathrm{~h}$ under nitrogen atmosphere and dialyzed against distilled water with dialysis membrane (molecular weight cut-off [MWCO] of 8-12 kDa) for 2 days followed by freeze-drying. CTS-Fmoc-GS with different degree of substitution (DS) was obtained by controlling the mole ratio of CTS and Fmoc-GS at 1:1 and 1:0.5.
Deprotection of Fmoc occurred spontaneously in the course of the reaction as already observed. ${ }^{27}$ About $50 \mathrm{mg}$ of CTS-Fmoc-GS was dissolved in $8 \mathrm{~mL}$ of distilled water with the addition of $30 \mu \mathrm{L}$ of piperidine at ambient temperature. The obtained solution was stirred for $1 \mathrm{~h}$ before extraction with twice volume of ethyl acetate and then was dissolved in distilled water with $3 \mathrm{~mL}$ of $1 \mathrm{M} \mathrm{HCl}$. CTS-GS was collected after dialysis against distilled water and freeze-drying.

The introduction of GSH to CTS-GS was conducted according to our previous report. ${ }^{28} \mathrm{CTS}-\mathrm{GS}(0.5 \mathrm{~g})$ was dissolved in $35 \mathrm{~mL}$ of distilled water. Then $5 \mathrm{~mL}$ of EDC, NHS and GSH solutions were separately added to the CTS-GS solution at a molar ratio of 5:5:3:2. The $\mathrm{pH}$ of resulting solution was adjusted to 5.0 with $0.1 \mathrm{M} \mathrm{NaOH}$. The mixture solution was stirred for $18 \mathrm{~h}$ under nitrogen atmosphere at room temperature followed by filtration. The resulting solution was dialyzed against $5 \mathrm{mM} \mathrm{HCl}$ for $18 \mathrm{~h}, 5 \mathrm{mM}$ $\mathrm{HCl}$ containing $1 \% \mathrm{NaCl}$ for $24 \mathrm{~h}$, and then $1 \mathrm{mM} \mathrm{HCl}$ for $24 \mathrm{~h}$. Finally, CG-GS was collected by adjusting $\mathrm{pH}$ to 4.0 with $0.1 \mathrm{M} \mathrm{NaOH}$ followed by freeze-drying.

\section{Characterization of CG-GS}

Both ${ }^{1} \mathrm{H}$ NMR and Fourier transform infrared spectroscopy (FTIR) were used to characterize the surface chemistry of the synthesized thiolated CTS derivative. ${ }^{1} \mathrm{H}$ NMR spectra were obtained using a Mercury Varian $400 \mathrm{MHz}$ spectrometer at $25^{\circ} \mathrm{C} ; \mathrm{D}_{2} \mathrm{O} / \mathrm{CF}_{3} \mathrm{COOH} / \mathrm{DMSO}$ was used to dissolve $5 \mathrm{mg}$ of CTS or the CTS derivatives. FTIR spectra were recorded on a Tensor-27 Infrared Spectroscopy (Bruker, Germany) and scanned over a range of 4,000-400 $\mathrm{cm}^{-1}$ with a resolution of $2 \mathrm{~cm}^{-1}$. The amount of thiol group in CG-GS was quantified spectrophotometrically using Ellman's test with a standard curve $\left(\mathrm{y}=3.8376 \mathrm{x}-0.0377, R^{2}=0.9998\right.$, where $\mathrm{x}$ was the concentration of GSH solution ranging from 0.03833 to $0.34498 \mu \mathrm{mol} / \mathrm{mL})^{29,30}$

\section{Preparation and physiochemical characterization of CG-GS-LDH hybrid nanocomposites}

Preparation of CG-GS-LDH hybrid nanocomposites PRN-loaded and FITC-labeled CG-GS-LDH hybrid nanocomposites were prepared by the coprecipitation hydrothermal method as described in our previous research with minor modifications. ${ }^{19}$ Briefly, PRN (140 mg, $0.4 \mathrm{mmol}$ ) was dissolved in $70 \mathrm{~mL}$ of deionized water and different amounts of CG-GS (37.5, 50 or $75 \mathrm{mg}$ ) was mixed with the above solution as reaction medium. Metal salt solution $(2 \mathrm{mM}, 2 \mathrm{~mL})$ of $\mathrm{Mg}\left(\mathrm{NO}_{3}\right)_{2} \bullet 6 \mathrm{H}_{2} \mathrm{O}$ and $\mathrm{Al}\left(\mathrm{NO}_{3}\right)_{3} \cdot 9 \mathrm{H}_{2} \mathrm{O}$ with $\mathrm{Mg} / \mathrm{Al}$ molar ratio of 2:1 and an aqueous solution of $\mathrm{NaOH}(13 \mathrm{mM}, 3 \mathrm{~mL})$ 
<smiles>CN(CC(=O)O)C(=O)CN(C)C(=O)COC1c2ccccc2-c2ccccc21</smiles>

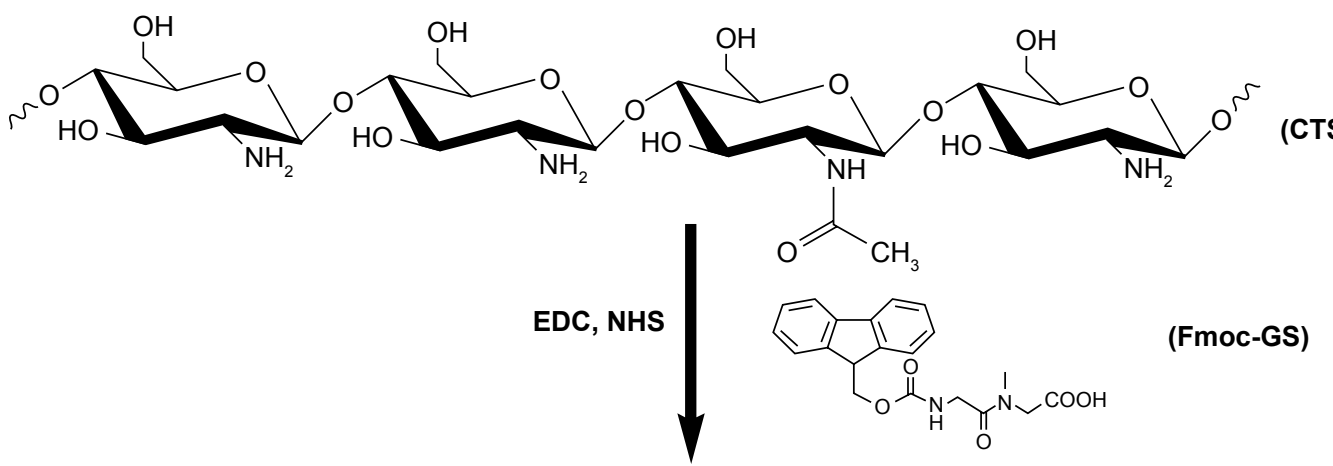

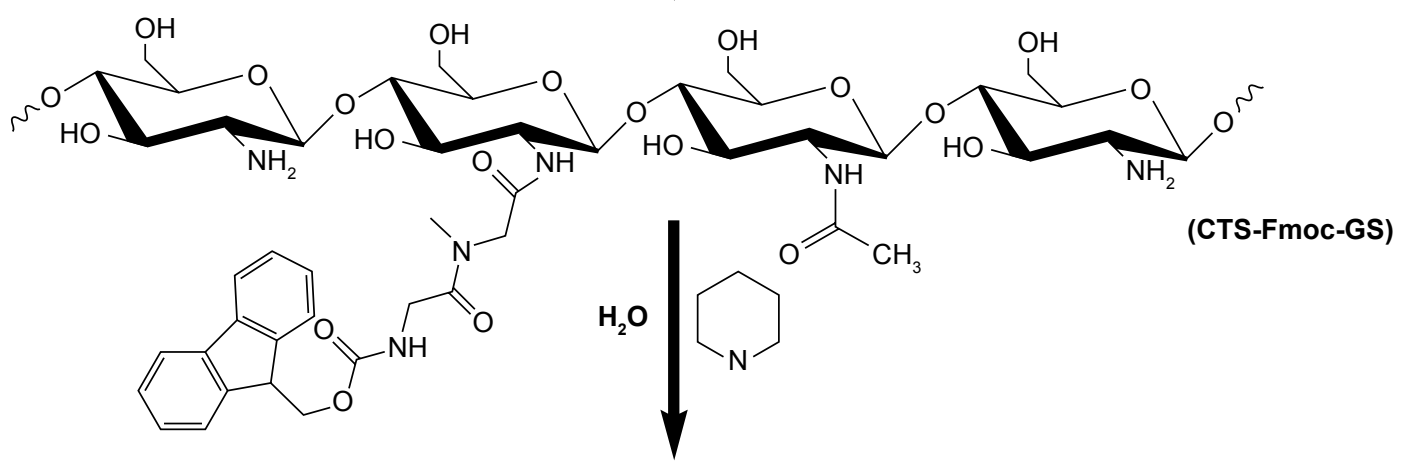

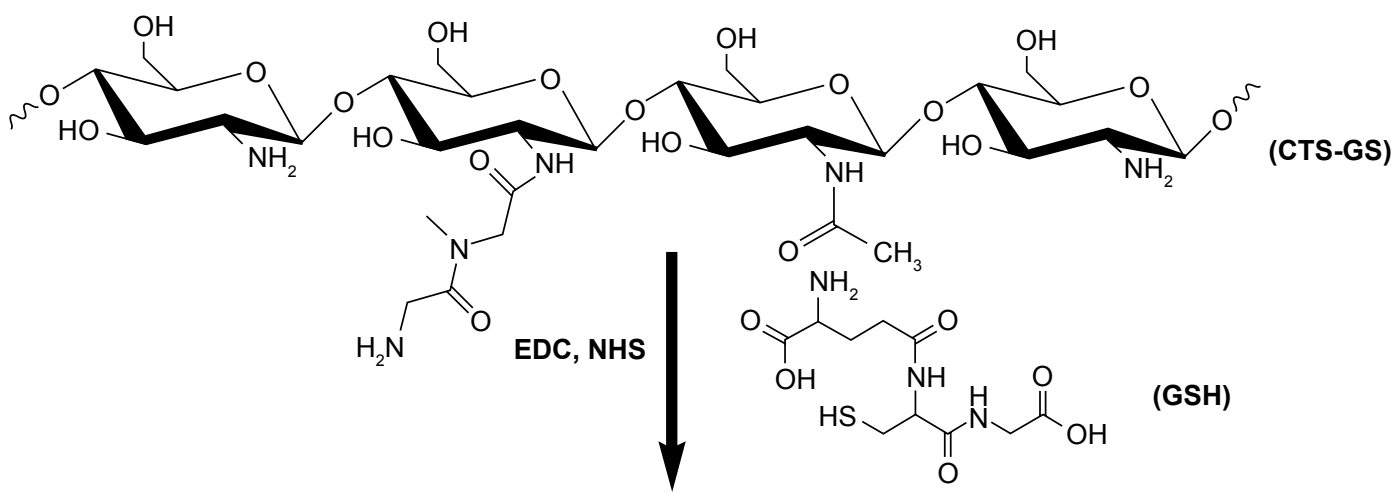

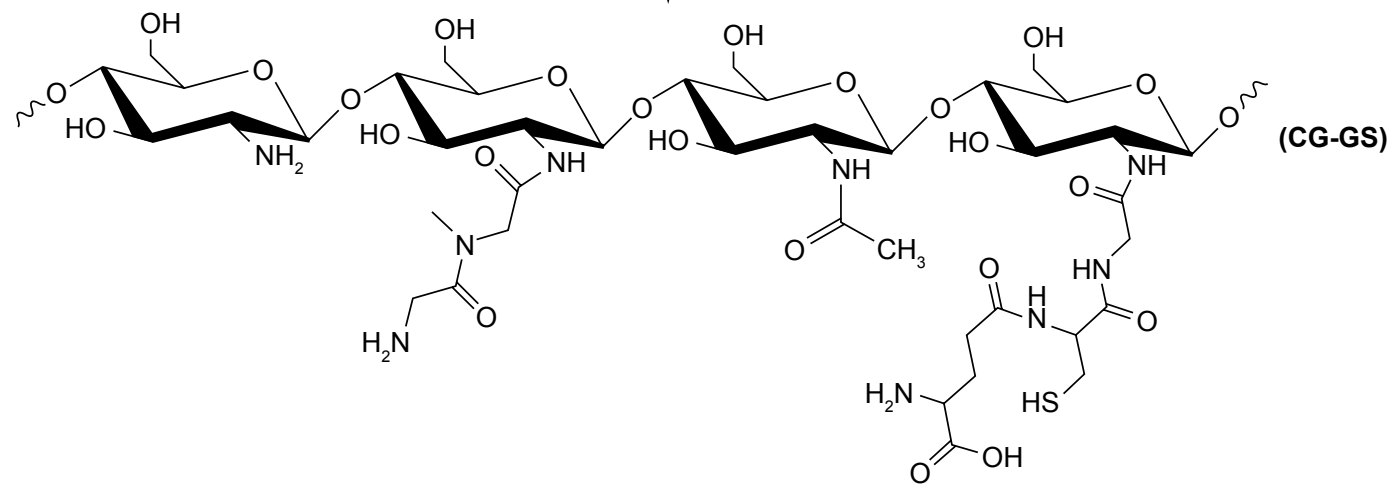

Scheme I Schematic reaction for the synthesis of chitosan-glutathione-glycylsarcosine (CG-GS).

Abbreviations: CTS, chitosan; CG-GS, chitosan-glutathione-glycylsarcosine; EDC, carbodiimide hydrochloride; Fmoc-OSu, Fmoc N-hydroxysuccinimide ester; GSH, L-glutathione reduced form; NHS, N-hydroxysuccinimide. 
were added drop wise simultaneously to the reaction medium under $\mathrm{N}_{2}$ atmosphere while vigorous stirring for $1 \mathrm{~h}$. The $\mathrm{pH}$ of the reaction solution was maintained at 9.0 with control of $1 \mathrm{M} \mathrm{NaOH}$. The slurry was recovered by centrifugation and dispersed in $60 \mathrm{~mL}$ of deionized water. Finally, $60 \mathrm{~mL}$ of the stable suspension was transferred into a Teflon-lined stainless-steel autoclave at $100^{\circ} \mathrm{C}$ for $5 \mathrm{~h}$. The product was vacuum-dried and denoted as CG-GS-PRN-LDH. Mg-Al$\mathrm{NO}_{3}$-LDH and PRN-LDH were prepared similarly except that the reaction medium was deionized water and deionized water with PRN, respectively. A variation of CG-GS-LDH nanocomposites (CG-GS-LDH-37.5, CG-GS-LDH-50, CGGS-LDH-75) was prepared.

The preparation of FITC-labeled CG-GS-LDH hybrid nanocomposites was as follows: CG-GS (50 mg) was dissolved in a $750 \mu \mathrm{L}$ of mixed salt solution of $\mathrm{Mg}\left(\mathrm{NO}_{3}\right)_{2} \cdot 6 \mathrm{H}_{2} \mathrm{O}$ $(0.038 \mathrm{~g}, 0.15 \mathrm{mmol})$ and $\mathrm{Al}\left(\mathrm{NO}_{3}\right)_{3} \bullet 9 \mathrm{H}_{2} \mathrm{O}(0.028 \mathrm{~g}$, $0.075 \mathrm{mmol})$, and then rapidly added into the stirring solution (2.5 mL) containing 0.6 M NaOH and $5 \mathrm{mg}$ FITC. Subsequently, the stirring suspension was centrifuged, washed and finally resuspended in $5 \mathrm{~mL}$ of deionized water.

\section{Physiochemical characterization of CG-GS-LDH hybrid nanocomposites}

The measurements of the particle size and zeta potential of the as-prepared products were taken on a ZetaSizer $3000 \mathrm{HS}$ laser particle size analyzer (Malvern, UK) at $25^{\circ} \mathrm{C}$ under a fixed angle of $90^{\circ}$. The morphology of the products was characterized by the transmission electron microscope (TEM; Hitachi H-7650, Tokyo, Japan) at an acceleration voltage of $200 \mathrm{kV}$. The phases and compositions of the products were characterized by X-ray diffractometer (XRD, Rigaku D/max2500/PC, $\mathrm{Cu} \mathrm{K} \alpha$ radiation, $\lambda=0.154 \mathrm{~nm}$; Rigaku Corporation, Tokyo, Japan), FTIR spectrometer (FTIR, Bruker, Germany) and thermogravimetric analyzer (TG209; Netzsch, Selb, Germany; heating rate $10^{\circ} \mathrm{C} / \mathrm{min}$, nitrogen flow).

The amount of PRN loaded in the CG-GS-LDH was defined as the equation $\%=\mathrm{W}_{\mathrm{d}} / \mathrm{W}_{\mathrm{t}} \times 100 \%$, where $\mathrm{W}_{\mathrm{d}}$ was the total drug content and $\mathrm{W}_{\mathrm{t}}$ was the amount of nanocomposites. About $5 \mathrm{mg}$ of CG-GS-PRN-LDH was dissolved in $2 \mathrm{~mL}$ of $5 \mathrm{M} \mathrm{HCl}$ followed by dilution to $10 \mathrm{~mL}$ with DMSO. The concentration of PRN was determined by a UV-vis spectrophotometer at a wavelength of $433 \mathrm{~nm}$. A standard curve of known concentration of PRN was used to calculate the concentration of intercalated drug $\left(\mathrm{y}=0.0597 \mathrm{x}-0.0006, R^{2}=0.9999\right)$.

\section{In vitro release study}

In vitro release of PRN from CG-GS-PRN-LDH nanocomposites was evaluated by paddle method as previously described. ${ }^{19}$ Briefly, artificial tear $(6.78 \mathrm{~g} / \mathrm{L} \mathrm{NaCl}, 2.18 \mathrm{~g} / \mathrm{L}$ $\mathrm{NaHCO}_{3}, 1.38 \mathrm{~g} / \mathrm{L} \mathrm{KCl}, 0.084 \mathrm{~g} / \mathrm{L} \mathrm{CaCl}_{2} \cdot 2 \mathrm{H}_{2} \mathrm{O}, \mathrm{pH} 7.4$ ) was employed as the release medium. Samples containing $10 \mathrm{mg}$ PRN were suspended in $900 \mathrm{~mL}$ of artificial tear and incubated at $35^{\circ} \mathrm{C} \pm 0.5^{\circ} \mathrm{C}$ with the speed at $100 \mathrm{rpm}$. At predetermined time intervals, $5 \mathrm{~mL}$ of solution was collected, filtered and then immediately replaced with the equal volume of fresh artificial tear. The released PRN in the medium was determined via UV-vis spectrophotometer at a wavelength of $433 \mathrm{~nm}$.

\section{In vitro cellular studies}

\section{Cytotoxicity assay}

The cytotoxicity of various nanocomposites (different DS of GS in CG-GS-LDH and CG-GS-PRN-LDH) on HCEpiC was evaluated using MTT assays. HCEpiC were seeded on 96 -well plates at a density of $2 \times 10^{4}$ cells per well. When $90 \%$ confluence was reached, the cells were treated with medium containing different nanocomposites with various concentrations of LDH carriers $(25,50,75,100$ and $200 \mu \mathrm{g} / \mathrm{mL})$. After incubation for $12 \mathrm{~h}$, the medium was removed and the cells were washed twice with Dulbecco's phosphatebuffered saline (DPBS; $\mathrm{pH} 7.4$ ), and then $180 \mu \mathrm{L}$ of culture medium and $20 \mu \mathrm{L}$ of MTT reagent $(5 \mathrm{mg} / \mathrm{mL}$ in DPBS) were added. The cells were incubated for an additional $4 \mathrm{~h}$ at $37^{\circ} \mathrm{C}$. The medium was removed and the MTT-formazan was dissolved in $150 \mu \mathrm{L}$ of DMSO. Finally, the OD values were measured at $570 \mathrm{~nm}$ using a microplate reader (Multiskan FC; Thermo Fisher Scientific, Waltham, MA, USA). Cell viability was expressed as the following formula:

$$
\text { Viability } \%=\frac{\mathrm{OD}_{\text {test }}-\mathrm{OD}_{\text {blank }}}{\mathrm{OD}_{\text {control }}-\mathrm{OD}_{\text {blank }}} \times 100 \%
$$

where $\mathrm{OD}_{\text {test }}$ represents the OD of wells exposed to the different nanocomposites, $\mathrm{OD}_{\text {control }}$ represents the OD of wells treated with supplement-free culture medium and $\mathrm{OD}_{\text {blank }}$ represents the OD of wells without any treatment.

\section{Inverted fluorescence microscope study}

To directly visualize the cellular uptake, HCEpiC were treated with FITC-labeled nanocomposites at different time periods. Typically, the cells were seeded in 24-well plates at a density of $5 \times 10^{4}$ cells per well and incubated at $37^{\circ} \mathrm{C}$ until they approached 90\% confluence. Subsequently, cells were washed with DPBS and incubated with different solutions (FITC solution, FITC-LDH nanoparticles, two different DS of GS in CG-GS-FITC-LDH or mixture of CG-GS and FITC solution) in the culture medium to give an equivalent of $2 \mu \mathrm{g} / \mathrm{mL}$ FITC. After incubation for 1,2 and $4 \mathrm{~h}$ at $37^{\circ} \mathrm{C}$, 
the samples were removed. The cells were rinsed three times with DPBS and observed with inverted fluorescence microscope (Nikon, Tokyo, Japan).

\section{Quantitative research of cellular uptake}

To quantify the cellular uptake, cells were incubated with PRN-loaded nanocomposites (PRN solution, PRN-LDH nanoparticles, two different DS of GS in CG-GS-PRN-LDH or mixture of CG-GS and PRN solution) at a concentration of $2 \mu \mathrm{g} / \mathrm{mL}$ for 1,2 and $4 \mathrm{~h}$, respectively. Then the test samples were removed and the cells were washed with DPBS followed by trypsinization and disruption with lysis buffer for $1 \mathrm{~h}$ at $4^{\circ} \mathrm{C}$. The lysate was then used to assay for PRN with a high-pressure liquid chromatography (HPLC) method and protein content assay (BCA assay kit; KeyGen BioTech, Nanjing, China). Cellular uptake was represented as the amount of PRN normalized with per mg of total cellular protein.

HPLC system employed in the study consisted of LC2010CHT (Shimadzu, Kyoto, Japan) with an LC-2010CHT variable wavelength UV-vis detector $\left(\lambda_{\text {detection }}=230 \mathrm{~nm}\right)$. A Diamonsil ${ }^{\circledR}$ Plus-C18 column $(4.6 \times 150 \mathrm{~mm}, 5 \mu \mathrm{m})$ (Dikma, Beijin, China) was operated at $35^{\circ} \mathrm{C}$. The mobile phase was composed of $\mathrm{NaH}_{2} \mathrm{PO}_{4}$-methanol-acetonitrile $(7: 2: 1, \mathrm{v} / \mathrm{v} / \mathrm{v})$ and was pumped at a flow rate of $1 \mathrm{~mL} / \mathrm{min}$.

\section{Investigation of cellular uptake mechanism}

The detailed uptake mechanisms have been explored in our group's previous work. ${ }^{20} \mathrm{HCEpiC}$ were incubated with endocytosis inhibitors at a certain concentration, which were not toxic to cells, ie, $2 \mathrm{mg} / \mathrm{mL}$ sodium azide, $0.45 \mathrm{M}$ hypertonic sucrose, and $10 \mu \mathrm{g} / \mathrm{mL}$ chlorpromazine. In addition, competitive inhibitor of GS (1, 5 and $10 \mathrm{mM}$ ) was also investigated. Following preincubation with inhibitors for $30 \mathrm{~min}$, freshly prepared FITClabeled nanocomposite suspensions were added and incubated for $4 \mathrm{~h}$. The fluorescence intensity was determined by flow cytometry (Miltenyi Biotec, Cologne, Germany). The uptake index (UI) was denoted as the relative percentage of uptake compared to the control without inhibitor pretreatment.

\section{Preparation and preliminary stability of CG-GS-LDH hybrid nanocomposite eye drops}

To comply with quality requirements of eye ophthalmic preparation, bacteriostatic agent of trichlorobutanol $(0.25 \%$ $\mathrm{w} / \mathrm{v})$ and osmotic pressure regulator of glucose $(6 \% \mathrm{w} / \mathrm{v})$ were added into $20 \mathrm{~mL}$ of CG-GS-PRN-LDH hybrid nanocomposite suspensions to give an equivalent of $50 \mu \mathrm{g} / \mathrm{mL}$ concentration of PRN.
The $\mathrm{pH}$ of different DS of GS in CG-GS-PRN-LDH nanocomposite eye drops was in the range of 8.0-8.5. The preparation of FITC-labeled nanocomposites has been described in section "Preparation of CG-GS-LDH hybrid nanocomposites". In addition, the preliminary stability of CG-GS-PRN-LDH hybrid nanocomposite eye drops was investigated at ambient temperature. The samples of the eye drops were analyzed for the changes in particle size, zeta potential, $\mathrm{pH}$ and the content of PRN at 0, 5 and 10 days.

\section{In vivo precorneal residence measurements}

With the aim to evaluate the precorneal retention effect of CG-GS with different amounts in CG-GS-PRN-LDH nanocomposites, CG-GS $(25,50 \mathrm{mg})$ was used in this experiment. Six New Zealand albino rabbits were randomly divided into two groups and each was given an instillation of $50 \mu \mathrm{L}$ of eye drops into the lower conjunctival sac of the left eye. The eyes were manually closed for $30 \mathrm{~s}$, and then $10 \mu \mathrm{L}$ of tear samples were collected by a capillary pipet at 10, 30, 60, 90, 120, 180, 240, 300 and $360 \mathrm{~min}$. Tear samples were directly diluted with $90 \mu \mathrm{L}$ methanol and vortexed for $2 \mathrm{~min}$, and then centrifuged at 10,000 rpm for $10 \mathrm{~min}$. The concentration of PRN in the supernatant was determined by HPLC as described in section "Quantitative research of cellular uptake".

\section{Ex vivo fluorescence image of rabbit ocular tissues}

For ex vivo fluorescence image study, $50 \mu \mathrm{L}$ of different FITC-labeled eye drops (FITC-LDH nanoparticles, different DS of GS in CG-GS-FITC-LDH nanocomposites and the mixture of CG-GS and FITC solution) were instilled into the lower conjunctival sac of each eye in rabbits. In order to acquire the highest distribution of FITC in ocular tissues, the same dosage of eye drops was administrated again after $2 \mathrm{~h}^{31}$ The untreated ocular tissues were used as a control. After another $2 \mathrm{~h}$, rabbits were sacrificed and the ocular tissues of cornea, iris-ciliary, crystalline lens and sclera were collected. The fluorescence intensity in different ocular tissues was detected by the In-Vivo FX Pro (Kodak, New Haven, CT, USA).

\section{In vivo tissue distribution study in rabbits}

The investigation with regard to biodistribution of CGGS-PRN-LDH hybrid nanocomposite eye drops in ocular tissues was performed using previously published protocol. ${ }^{19}$ Briefly, $50 \mu \mathrm{L}$ of CG-GS-PRN-LDH hybrid nanocomposite eye drops containing $2.5 \mu \mathrm{g}$ of PRN were added in two 
instillations at 10 min intervals using a micropipette without actually touching the eyes and irritating the corneal surface. At $0.5,2,4,6$ and $8 \mathrm{~h}$ (three eyes/time point) following the administration, rabbits were sacrificed and $300 \mu \mathrm{L}$ of the aqueous humor from each eye was taken by microinjector. Then the sclera, cornea, iris-ciliary and crystalline lens were isolated and washed with normal saline. The tissue samples were placed into plastic vacuum blood collection tubes followed by drying with filter paper which were later weighed. Subsequently, the biosamples except aqueous humor were mixed with $500 \mu \mathrm{L}$ of normal saline and homogenized with homogenizer (F6-10-8G; Fluko, Shanghai, China) on an ice bath, until the tissues were completely homogenized. Aqueous humor samples were directly diluted with $300 \mu \mathrm{L}$ of methanol and the rest of ocular tissue homogenates were diluted with $500 \mu \mathrm{L}$ of methanol followed by vortexing for $2 \mathrm{~min}$, and then centrifuged at $10,000 \mathrm{rpm}$ for $10 \mathrm{~min}$. Aliquots of the supernatants were analyzed by the HPLC method as described in section "Quantitative research of cellular uptake".

\section{Evaluation of eye irritancy}

To assess the potential risk of ocular irritation caused by nanocomposites, ocular tolerance test by in vivo and in vitro methods was carried out ( $n=3$ /group). Each rabbit was treated with $50 \mu \mathrm{L}$ of different DS of GS in CG-GS-PRN-LDH hybrid nanocomposite eye drops, which were applied to the lower conjunctival sac of the left eye thrice daily for a 7-day period, while the right eye was treated with normal saline as a control. In vivo ocular tolerance assays were performed using Draize irritation test by direct observation of the anterior segment of the eye, noting the possible injury of the conjunctiva (inflammation, chemosis, redness or oozing), iris and cornea (opacity and affected surface) (for details see Table S1). Ocular irritation index (OII) was evaluated according to the observed injuries (Table S2). ${ }^{32-34}$ Following completion of in vivo ocular tolerance assays, all the rabbits were euthanized by air embolism. Then cornea, conjunctiva and iris of the ocular tissues were fixed with 10\% formaldehyde. Sections were cut from the paraffin blocks at a thickness of $5 \mu \mathrm{m}$ and stained with hematoxylin and eosin. In vitro histopathological examination was performed with a light microscope to examine the changes in epithelial and basal cells.

\section{Statistical analysis}

All experiments were conducted at least in triplicate; data were presented as mean $\pm \mathrm{SD}$. Comparisons between groups were made using one-way ANOVA, followed by Student's $t$-test. Statistically significant difference was set at $P<0.05$.
GraphPad Prism 6 software was used to carry out the analysis.

\section{Results and discussion Characterization of CG-GS}

\section{Proton nuclear magnetic resonance}

The chemical structures of CG-GS and intermediates were characterized by ${ }^{1} \mathrm{H}$ NMR, as shown in Figure 1 . The peaks at chemical shifts 3.5-4.5, 3.0 and 2.0 ppm were ascribed to the H2, H3-H6 and acetyl protons in the CTS skeleton (Figure 1h), respectively. For Fmoc-GS (Figure 1i) and CTS-Fmoc-GS (Figure $1 \mathrm{f}$ and $\mathrm{g}$ ), the appearance of new peak at 7.16-7.96 ppm corresponded to the aromatic protons of Fmoc-OSu. Meanwhile, no signal of aromatic segment was observed in CTS-GS (Figure 1d and e). These results suggested that Fmoc-GS was grafted onto CTS and deprotected successfully. The DS of GS in CG-GS (1:0.5) and CG-GS (1:1) was determined by ${ }^{1} \mathrm{H}$ NMR spectroscopy using the ratio of the area of the proton signals at 7.16-7.96 ppm and $3.0 \mathrm{ppm}$, which was $8.7 \%$ and $14.5 \%$, respectively. The amount of free thiol groups in the CG-GS (1:0.5) and CG-GS

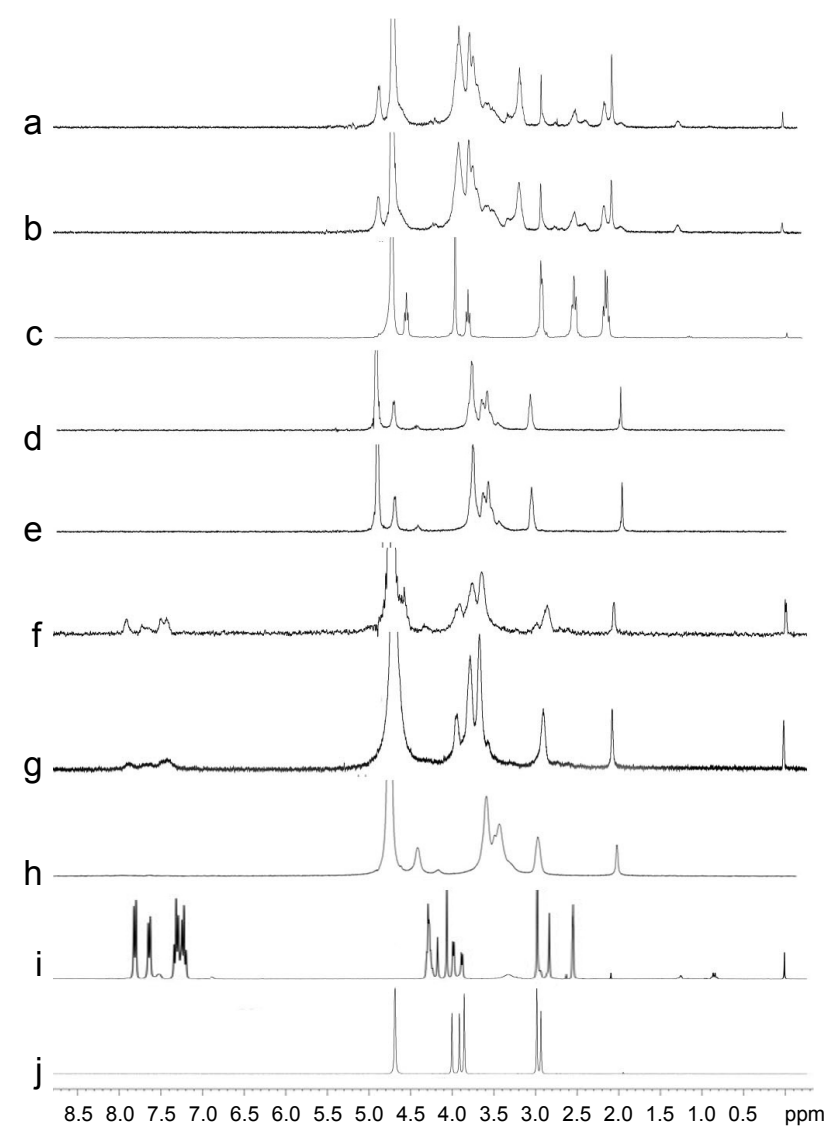

Figure I 'H NMR spectra of CG-GS (I:I) (a), CG-GS ( I:0.5) (b), GSH (c), CTS-GS (I:I) (d), CTS-GS (I:0.5) (e), CTS-Fmoc-GS (I:I) (f), CTS-Fmoc-GS (I:0.5) (g), CTS (h), Fmoc-GS (i) and GS (j).

Abbreviations: CTS, chitosan; CG-GS, chitosan-glutathione-glycylsarcosine; Fmoc, ; $\mathrm{GSH}$, L-glutathione reduced form; 'H NMR, proton nuclear magnetic resonance. 
(1:1) was found to be 414.8 and $375.1 \mu \mathrm{mol} / \mathrm{g}$, respectively. Overall, the ${ }^{1} \mathrm{H}$ NMR spectra confirmed that CG-GS was successfully synthesized.

\section{FTIR}

The FTIR spectra of CTS and its derivatives are presented in Figure $\mathrm{S} 1$. The CTS showed absorption at $1,658 \mathrm{~cm}^{-1}\left(\mathrm{v}_{\mathrm{C}=\mathrm{O}}\right.$, amide I vibration), $1,597 \mathrm{~cm}^{-1}\left(\delta_{\mathrm{N}-\mathrm{H}}\right.$, amide II vibration) and $1,324 \mathrm{~cm}^{-1}\left(\mathrm{v}_{\mathrm{C}-\mathrm{N}}\right.$, amide III vibration). For the CTS derivatives, the intensities of amide I vibration and amide II vibration increased dramatically. It is probably due to the amide coupling between CTS and peptides. This finding also exhibited the successful conjugation of thiolated CTS and GS.

\section{Physiochemical characterization of CG-GS-LDH hybrid nanocomposites TEM}

TEM images (Figure S2) indicated a hexagonal plateletshaped structure of blank LDH (A) and CG-GS-PRN-LDH (B) with a diameter of $\sim 100 \mathrm{~nm}$ and $\sim 200 \mathrm{~nm}$, respectively. The average particle size measured by particle size analyzer was $96.4 \pm 3.9 \mathrm{~nm}$ and $158.3 \pm 2.6 \mathrm{~nm}$, respectively, which was almost the same as the size visualized by TEM.

\section{FTIR}

As shown in Figure 2, all the LDH samples demonstrated an intense broadband at $3,456 \mathrm{~cm}^{-1}$, associated with the stretching

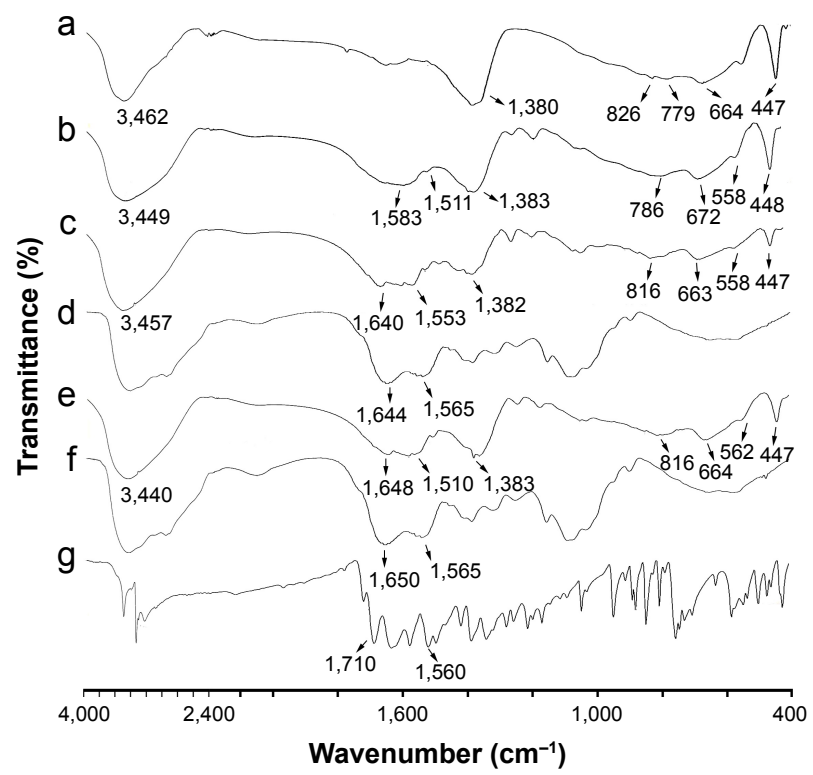

Figure 2 IR patterns of Mg-AI-NO ${ }_{3}$-LDH (a), Mg-Al-PRN-LDH (b), CG-GS-PRNLDH (l:0.5) (c), CG-GS (I:0.5) (d), CG-GS-PRN-LDH (l:I) (e), CG-GS (I:I) (f) and PRN (g).

Abbreviations: CG-GS, chitosan-glutathione-glycylsarcosine; IR, infrared; LDH, layered double hydroxides; PRN, pirenoxine sodium. vibration of the hydroxyl groups in LDH layers and absorbed water molecules. A series of bands recorded in the $400-900 \mathrm{~cm}^{-1}$ region were ascribed to the $\mathrm{M}-\mathrm{O}$ and $\mathrm{O}-\mathrm{M}-\mathrm{O}(\mathrm{M}=\mathrm{Mg}, \mathrm{Al})$ vibrations. ${ }^{35}$ After loading PRN into the LDH samples, the absorption intensity of nitrate group at $1,384 \mathrm{~cm}^{-1}$ was lower than that of blank LDH samples, indicating the replacement of $\mathrm{NO}_{3}{ }^{-}$with PRN anion. The characteristic peaks of pure PRN were absent in PRN-LDH (Figure 2b) and CG-GS-PRN-LDH (Figure $2 \mathrm{c}$ and e), while the additional peaks at 1,585 and $1,507 \mathrm{~cm}^{-1}$ originated from $-\mathrm{COO}^{-}$could be observed, thus confirming the intercalation of PRN anions inside layers. Two characteristic peaks of CG-GS (Figure $2 \mathrm{~d}$ and $\mathrm{f}$ ) were located at 1,651 and 1,565 $\mathrm{cm}^{-1}$, namely Amide I and Amide II. Notably, these absorption bands of CG-GS-PRN-LDH (Figure 2c and e) were red-shifted compared to those of CG-GS. These results indicated that as-prepared CG-GS-PRN-LDH was a structure of CG-GS partly intercalated with LDH nanocomposites.

\section{XRD}

The XRD patterns of pristine LDH and PRN-loaded LDH nanocomposites with different weights of CG-GS are displayed in Figure 3, exhibiting characteristic reflections of crystallized lamellar materials. The formation of LDH was

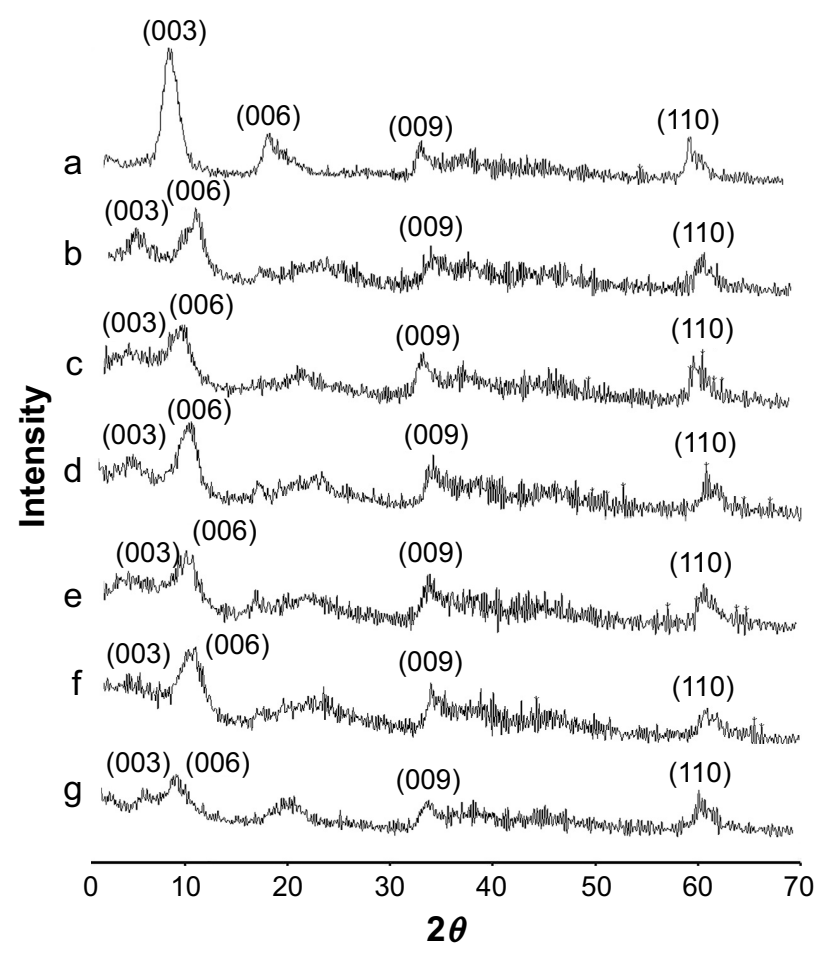

Figure 3 XRD pattern of blank LDH (a), Mg-Al-PRN-LDH (b), CG-GS-PRN-LDH ( I:0.5)-50 (c), CG-GS-PRN-LDH (I:I)-37.5 (d), CG-GS-PRN-LDH (I:I)-50 (e), CGGS-PRN-LDH (I:I)-75 (f) and physical mixture of Mg-Al-PRN-LDH and CG-GS (1:0.5)-50 (g).

Abbreviations: CG-GS, chitosan-glutathione-glycylsarcosine; LDH, layered double hydroxides; PRN, pirenoxine sodium; XRD, X-ray diffractometer. 
evidenced by the basal planes obtained from (003), (006), (009) and (110), corresponding to the crystalline solids with regular layered structure. The basal spacing of (003) reflection in blank LDH (Figure 3a) was $8.8 \AA$ calculated by (001) reflection, which could be attributed to the $\mathrm{NO}_{3}^{-}$guests in the interlayer region. ${ }^{36}$ When PRN is being intercalated, as shown in Figure 3b, the (003) basal reflection shifted to lower $2 \theta$ angle from $10^{\circ}$ to $7^{\circ}$, corresponding to an increase of the interlayer distance from $8.8 \AA$ to $12.7 \AA$. This result indicated that PRN was intercalated into the galleries of $\mathrm{LDH}$. The shift of (003) basal reflection has also been observed in different DS and amount of CG-GS in CG-GS-PRN-LDH hybrid nanocomposites and the physical mixture of $\mathrm{Mg}-\mathrm{Al}-$ PRN-LDH and CG-GS (Figure 3c-g). The basal spacing of CG-GS-PRN-LDH-50 (1:0.5) and CG-GS-PRN-LDH-50 (1:1) was $13.7 \AA$ and $14.0 \AA$, respectively. Therefore, similar basal spacing was obtained in CG-GS-PRN-LDH at 1:0.5 and $1: 1 \mathrm{CG} / \mathrm{GS}$ mole ratio when the amount of CG-GS was kept constant. On the other hand, the basal spacing was $13.5 \AA$, $14.0 \AA$ and $14.9 \AA$ for CG-GS-PRN-LDH-37.5 (1:1), CGGS-PRN-LDH-50 (1:1) and CG-GS-PRN-LDH-75 (1:1), respectively. The basal spacing expanded with the increasing amount of CG-GS when the mole ratio of CG/GS was kept constant. These results suggested that partial CG-GS was intercalated into the interlayer gallery instead of being absorbed on the surface simply, probably due to CG-GS through detaching protons from carboxylic acid residues in the alkaline solution, thereby inducing a negative charge at CG-GS side chain. It was reported that the polymer could be intercalated into the interlayer space of layered materials when they possessed strong and periodic negative charge on the backbone. ${ }^{37,38}$ It is important to mention that similar gallery heights have been observed for Mg-Al-PRN-LDH and the physical mixture of Mg-Al-PRN-LDH and CG-GS, indicating that CG-GS only coated Mg-Al-PRN-LDH nanocomposites without intercalation. These results all confirmed organic-intercalated inorganic hybrid LDH nanocomposites of CG-GS-PRN-LDH were prepared successfully.

\section{TG}

TG analyses of pure PRN and all LDH samples are shown in Figure S3. Weight loss in PRN occurred in three temperature regions of $50^{\circ} \mathrm{C}-100^{\circ} \mathrm{C}, 100^{\circ} \mathrm{C}-400^{\circ} \mathrm{C}$ and $400^{\circ} \mathrm{C}-500^{\circ} \mathrm{C}$, because of dehydroxylation of water molecules and oxidative decomposition gradually. The weight loss behavior for different amounts of CG-GS for CG-GS-PRN-LDH, PRNLDH and the physical mixture of PRN-LDH and CG-GS was almost similar to that of blank LDH. Three stages of weight loss were clearly observed for these samples. The first step of weight loss occurred from $25^{\circ} \mathrm{C}$ to $200^{\circ} \mathrm{C}$ with $\sim 12 \%$ weight loss, corresponding to the dehydration of physical absorbed water on the surface and hydrogen bonding water in the interlayer. The second weight loss occurred in the range of $300^{\circ} \mathrm{C}-400^{\circ} \mathrm{C}$, which was attributed to the dehydroxylation of the hydroxyl groups within the layers and/or degradation of polymers, with $\sim 16 \%$ weight loss. The third weight loss took place in the temperature region of $400^{\circ} \mathrm{C}-550^{\circ} \mathrm{C}$ which accounted for $\sim 12 \%$ weight loss resulting from the elimination of $\mathrm{NO}_{3}^{-}$in the interlayer and/or oxidative decomposition of PRN. The final decomposition products were those obtained by the crystallization of $\mathrm{MgO}, \mathrm{MgAl}_{2} \mathrm{O}_{4}$ and $\mathrm{Al}_{2} \mathrm{O}_{3}$ at a temperature of $550^{\circ} \mathrm{C} .{ }^{39}$

\section{Physiochemical properties}

As summarized in Table 1, no distinct difference was found in the particle size, zeta potential, $\mathrm{pH}$ and drug loading of different DS. Surface charge was attributed to physical stability in a dispersed system, which may create repelling forces among the particles, increasing overall stability of the solution. ${ }^{40}$ Zeta potential of all samples was above $30 \mathrm{mV}$ in positive values, promoting the retention of nanocomposites at the corneal surface and stabilizing the nanosystem.

\section{In vitro release study}

From Figure 4, we could see that all LDH samples exhibited a fast release stage at the initial $45 \mathrm{~min}$ followed by a relatively slow release during 45-300 min until a constant release percentage at $6 \mathrm{~h}$. Thus the whole release process could be divided into three stages. In stage I, the initial fast release might be ascribed to the dissociation from the surface of $\mathrm{LDH}$. The stage II was the rate-controlling step, which was due to the ion-exchange of PRN anions from the interlayer space of LDH with the anions in the medium under the action of concentration gradient. In stage III, the sluggish release was observed

Table I Characterization of different kinds of CG-GS-PRN-LDH nanocomposites (mean \pm SD, $n=3$ )

\begin{tabular}{|c|c|c|c|c|}
\hline Samples & Particle size (nm) & Zeta potential (mV) & pH & Drug loading (\%) \\
\hline CG-GS-PRN-LDH ( $1: 0.5)-50$ mg & $155.8 \pm 1.4$ & $+45.32 \pm 1.96$ & $8.37 \pm 0.25$ & $6.05 \pm 0.36$ \\
\hline CG-GS-PRN-LDH (I:I)-50 mg & $158.3 \pm 2.6$ & $+43.6 \mathrm{I} \pm 2.37$ & $8.46 \pm 0.12$ & $5.97 \pm 0.5 \mathrm{I}$ \\
\hline
\end{tabular}

Abbreviations: CG-GS, chitosan-glutathione-glycylsarcosine; LDH, layered double hydroxides; PRN, pirenoxine sodium. 

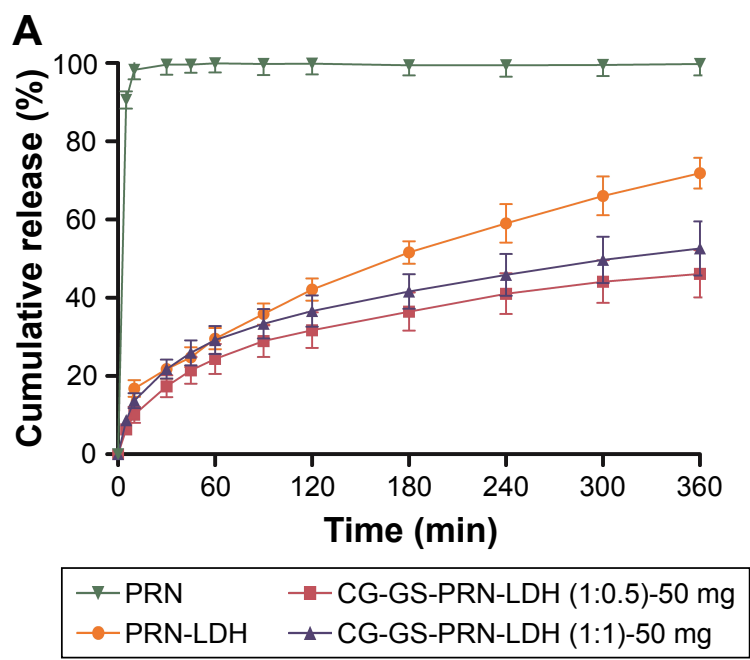

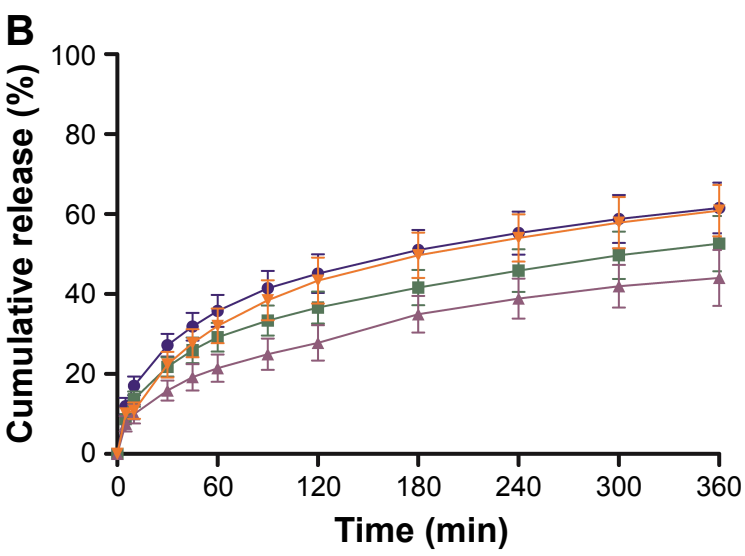

$\rightarrow-$ CG-GS-PRN-LDH (1:1)-37.5 mg
$\rightarrow-$ CG-GS-PRN-LDH (1:1)-75 mg
$\rightarrow-$ CG-GS-PRN-LDH (1:1)-50 mg
$\rightarrow-$ Physical mixture of CG-GS and PRN-LDH

Figure 4 Release profiles of PRN, PRN-LDH, different DS of GS (A) and the amount of CG-GS (B) for CG-GS-PRN-LDH nanocomposites in artificial tears (mean \pm SD, $\mathrm{n}=3$ ).

Abbreviations: CG-GS, chitosan-glutathione-glycylsarcosine; DS, degree of substitution; LDH, layered double hydroxides; PRN, pirenoxine sodium.

because the layered structure collapsed and only a little PRN could be liberated from it. ${ }^{41}$ Both PRN-LDH and CG-GSPRN-LDH exhibited obvious sustained release fashion when compared to pure PRN. The cumulative release percentage of PRN from CG-GS-PRN-LDH was $45 \%-60 \%$ at $6 \mathrm{~h}$, which was slightly lower than that of PRN-LDH. Additionally, the cumulative release percentage of CG-GS-PRN-LDH (1:1) was slightly higher than that of CG-GS-PRN-LDH (1:0.5) when the amount of CG-GS was kept constant (Figure 4A). This might be attributed to the higher thiol content of CGGS-PRN-LDH (1:0.5) than that of CG-GS-PRN-LDH (1:1), which could enhance the cohesion of layered structure. This closely stacked LDH might increase the release resistance and further reduce the cumulative release amount. The cumulative amount of PRN released from CG-GS-PRN-LDH-37.5, CGGS-PRN-LDH-50 and CG-GS-PRN-LDH-75 was gradually reduced, corresponding to the increased amount of CG-GS (Figure 4B). This was probably due to the enhanced cohesion and thus slightly stronger host (CG-GS-LDH)-guest (PRN) interaction when the amount of CG-GS was increased. Meanwhile, physical mixture of CG-GS and PRN-LDH exhibited higher cumulative percentage compared with the CG-GSPRN-LDH-50. This also illustrated CG-GS was hybrid with LDH instead of being absorbed on the surface.

\section{In vitro cellular studies}

\section{Cytotoxicity assay}

In vitro cytotoxic effect of PRN-loaded and blank CG-GSLDH nanocomposites in HCEpiC are presented in Figure S4. The different DS of CG/GS showed no obvious influence on the cell viability. The survival rate of HCEpiC was decreased with increasing concentration of nanocomposite carrier of LDH. The cytotoxicity might be attributed to the depression of S phase in cell cycle. ${ }^{42}$ For both CG-GS-PRN-LDH and CG-GS-LDH, a high degree of cell viability $(>80 \%)$ was exhibited at the concentration range of $0-75 \mu \mathrm{g} / \mathrm{mL}$ after $12 \mathrm{~h}$ of cultivation, which was in agreement with the results of our previous study. ${ }^{20}$ Jian et al has reported that the relatively high positive charge will not affect cellular morphology and membrane integrity. ${ }^{43}$ Therefore, these results revealed that the nanocomposites exhibited good biocompatibility and the concentration of LDH carriers less than $75 \mu \mathrm{g} / \mathrm{mL}$ should be a safe level for further cellular studies.

\section{Inverted fluorescence microscope study}

To achieve effective delivery through the cornea, the cellular uptake efficiency of CG-GS-LDH was evaluated by inverted fluorescence microscope observation. As shown in Figure 5, the fluorescence signals of CG-GS-FITC-LDH versus time were dramatically increased from 1 to $4 \mathrm{~h}$, confirming that the uptake of CG-GS-FITC-LDH by HCEpiC was dependent on the incubating time. Both CG-GS-FITCLDH (1:0.5) (Figure 5a) and CG-GS-FITC-LDH (1:1) (Figure 5b) exhibited enhanced intracellular fluorescence signals, and no significant difference on cellular uptake was observed. Comparatively, the fluorescence intensity of CGGS-FITC-LDH (1:1) was much stronger than that of free FITC solution (Figure 5e). In addition, the higher intracellular fluorescence intensity of CG-GS-FITC-LDH (1:1) was observed compared to that of the mixture of CG-GS (1:1) 

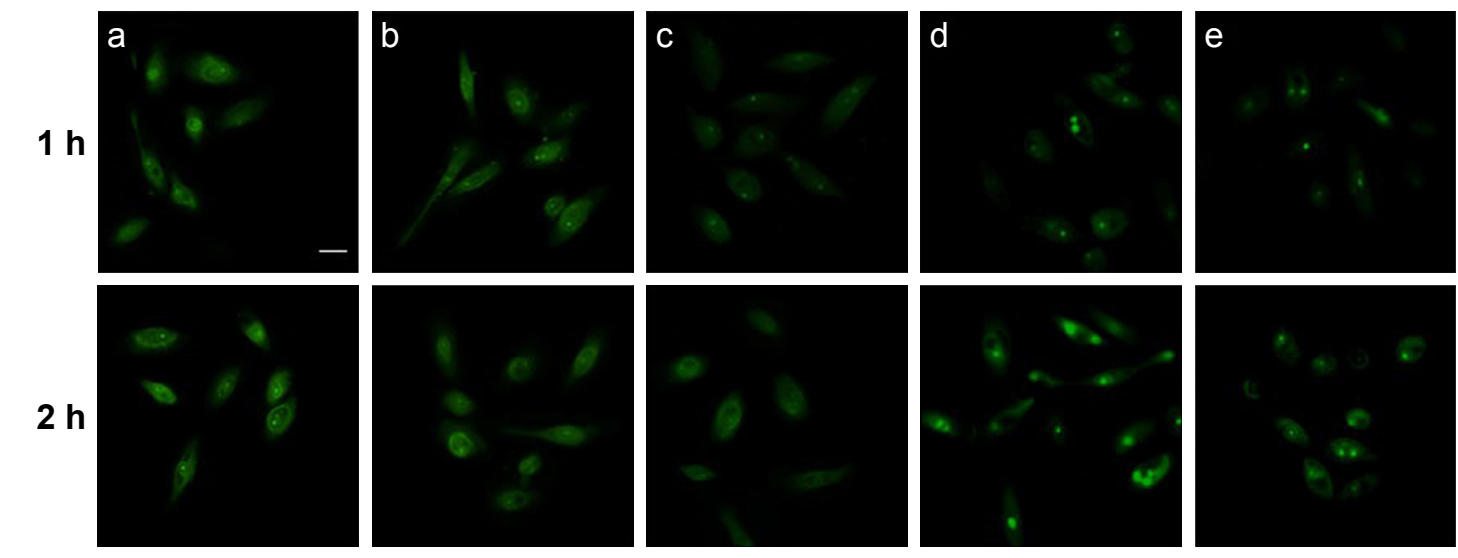

$2 \mathrm{~h}$
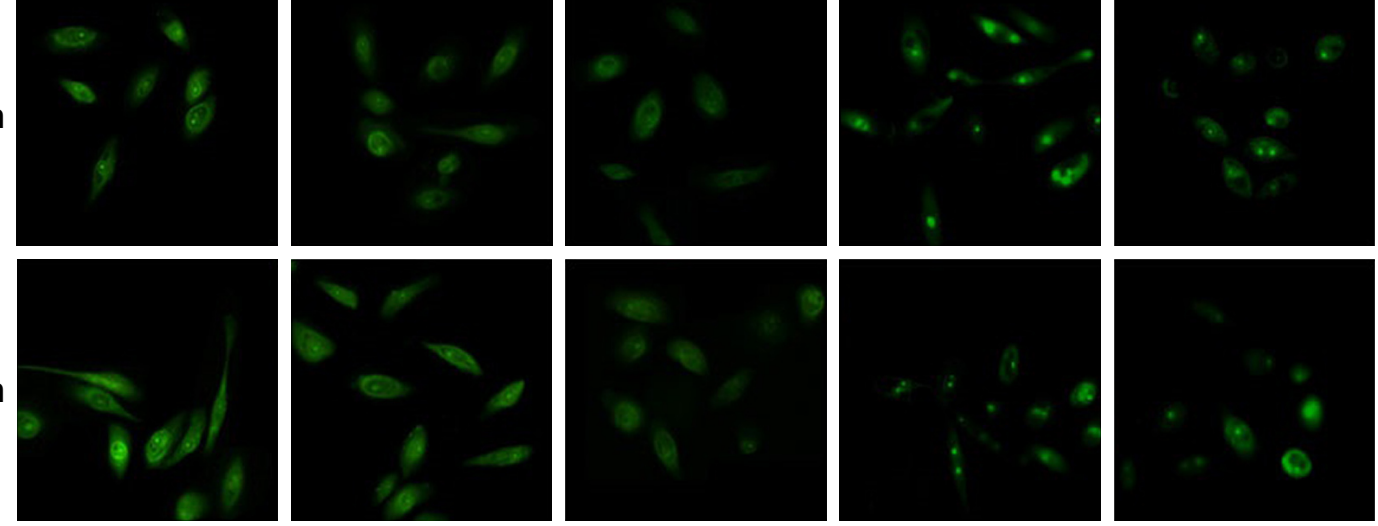

Figure 5 Fluorescence microscopy images of HCEpiC incubated with CG-GS-FITC-LDH (I:I) nanocomposites (a), CG-GS-FITC-LDH (I:0.5) nanocomposites (b), physical mixture of CG-GS and FITC solution $(0.00038 \%$ [w/v]) (c), FITC-LDH nanoparticles (d) and FITC solution (e) at different times. Scale bar $=25 \mu \mathrm{m}$.

Abbreviations: CG-GS, chitosan-glutathione-glycylsarcosine; FITC, fluorescein isothiocyanate Isomer I; HCEpiC, human corneal epithelial primary cells; LDH, layered double hydroxides.

and FITC solution (Figure 5c). The facilitated cellular uptake was achieved by the intercalated nanocomposites based on CG-GS and LDH, which was probably due to the enhanced bioadhesion on the cell membrane and the sustained release of the fluorescence probe.

\section{Quantitative research of cellular uptake}

By quantifying the cellular uptake profile of nanoparticles, internalized PRN content within cultured HCEpiC was determined by HPLC (Figure S5). The analyses showed increased PRN content within $4 \mathrm{~h}$ in HCEpiC for CG-GS-PRN-LDH nanocomposites compared to the physical mixture of CG-GS and PRN, which was in accordance with the inverted fluorescence microscope study. For CG-GS-PRN-LDH (1:1) and CG-GS-PRN-LDH (1:0.5) with an equivalent amount of PRN $(2 \mu \mathrm{g} / \mathrm{mL})$, the UI at $4 \mathrm{~h}$ was up to 3.43 - and 3.03 -fold higher than that of PRN solution, and 1.73- and 1.54-fold higher than that of PRN-LDH nanoparticles, respectively. However, there was no significant difference in uptake amount among different graft ratios of GS at given time points. The maximum in vitro uptake amount was found in CG-GS-PRN-LDH (1:1) with higher graft ratio of GS, which was significantly higher than that of PRN-LDH nanoparticle $(P<0.05)$, and 2.53-fold enhancement compared to that of the physical mixture of CG-GS and PRN after $4 \mathrm{~h}$ of incubation. These results indicated that CG-GS-PRN-LDH were taken up by HCEpiC and had the potential to deliver more PRN through the cornea. The improved cellular uptake efficacy of CG-GS-PRN-LDH might be attributed to the fact that GS, a specific PepT-1 ligand, could improve the cellular uptake of these nanocomposites. ${ }^{44}$

\section{Investigation of cellular uptake mechanism}

In our group's previous work, we have illustrated that clathrinmediated endocytosis was involved in the internalization of LDH nanoparticles. ${ }^{20}$ To further verify the mechanism involved in the uptake of CG-GS-LDH nanocomposites, cellular uptake mechanisms were investigated by utilizing endocytic inhibitors. CG-GS-FITC-LDH nanocomposites were coincubated with sodium azide for $4 \mathrm{~h}$, and the fluorescence internalized into the cells was significantly reduced $(P<0.001)$, implying an energy-dependent process was involved in the transport (Figure S6). Meanwhile, a significant reduction of transport was observed in the presence of hypertonic sucrose $(P<0.001)$ and chlorpromazine $(P<0.05)$, proving a clathrin-mediated endocytosis pathway, which is consistent with our previous work and work by $\mathrm{Oh}$ et al. ${ }^{45}$

To further elucidate the specific interaction of CGGS-LDH nanocomposites with PepT-1 expressed on the HCEpiC, ${ }^{10,46}$ competitive binding experiments were performed by pretreating cells with free GS solution to block PepT-1 prior to incubating with different DS of GS in CGGS-LDH (Figure 6). ${ }^{47}$ All GS with the concentration of 1, 5 

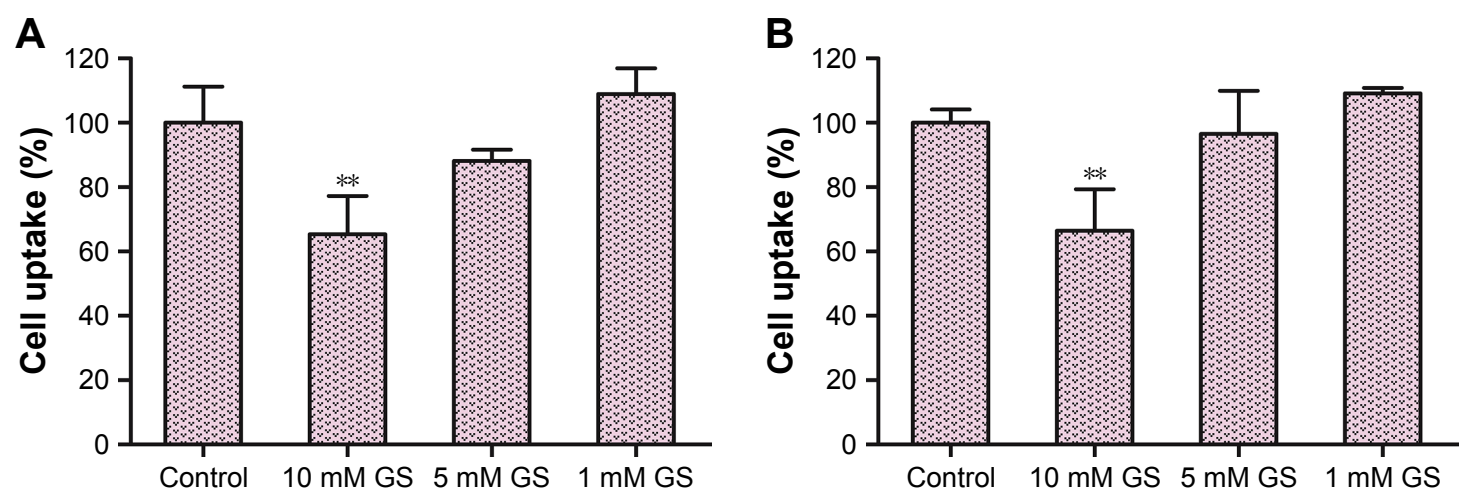

Figure 6 The effects of different concentrations of GS on cellular uptake of CG-GS-FITC-LDH (I:0.5) nanocomposites (A) and CG-GS-FITC-LDH (I:I) nanocomposites (B) (mean $\pm \mathrm{SD}, \mathrm{n}=3$ ); ** $\mathrm{P}<0.01$ versus control group.

Abbreviations: CG-GS, chitosan-glutathione-glycylsarcosine; FITC, fluorescein isothiocyanate Isomer I; LDH, layered double hydroxides.

and $10 \mathrm{mM}$ showed no cytotoxicity as demonstrated in our group's previous work. ${ }^{20}$ CG-GS-FITC-LDH nanocomposites exhibited no significant difference in cellular uptake in the presence of 1 and $5 \mathrm{mM}$ GS compared to CG-GS-FITCLDH nanocomposites alone. However, the internalization of different DS of GS in CG-GS-FITC-LDH nanocomposites was significantly inhibited by $10 \mathrm{mM}$ GS $(P<0.01)$. The reduction of internalization could be the result of the specific PepT-1-binding competition. Other previous report also showed that dipeptide Ser-Glu had high specificity to PepT-1, which could act as an active target ligand to functionalize nanoparticles for tumor-targeted drug delivery. ${ }^{48}$ Overall, these results confirmed that the active transport by PepT-1 and clathrin-mediated endocytosis might be involved in the cellular uptake of CG-GS-LDH nanocomposites.

\section{Preliminary stability of CG-GS-PRN-LDH hybrid nanocomposite eye drops}

The particle size, zeta potential, $\mathrm{pH}$ and the content of CG-GS-PRN-LDH (1:1)-50 hybrid nanocomposite eye drops were $161.5 \pm 1.6 \mathrm{~nm},+41.72 \pm 1.84 \mathrm{mV}, 8.03 \pm 0.09$ and $99.4 \% \pm 0.6 \%$ at 0 day, respectively. At 5 days, physiochemical properties remained almost the same as in the beginning. At 10 days, the particle size, zeta potential, $\mathrm{pH}$ and the PRN content were $165.4 \pm 1.5 \mathrm{~nm},+37.98 \pm 1.31 \mathrm{mV}, 8.12 \pm 0.12$ and $97.1 \% \pm 0.8 \%$, respectively. There was no obvious change in the nanocomposites and they were suitable for the following studies.

\section{In vivo precorneal residence measurements}

Precorneal retention was measured to evaluate the residence of drug in the precorneal area and predict the potential of drug from the formulations permeated through the cornea in vivo. ${ }^{49}$ To investigate the influence of the amount of CG-GS in CG-GS-PRN-LDH nanocomposites in terms of prolonging residence at the target site of cornea, different amounts of CG-GS were used in in vivo precorneal retention evaluation. Figure 7 represents the PRN concentration in rabbit tears versus time profiles. Therein, the data of commercial product and PRN-LDH eye drops were published in our previous report. ${ }^{19}$ Although the general profile of all these PRN concentrations from the two CG-GS-PRN-LDH, PRN-LDH and commercial product versus time curves was similar, the PRN concentration from the CG-GS-PRN-LDH (1:1)-50 nanocomposite eye drops was significantly increased compared to that of commercial product at every time point $(P<0.05)$. Individually, the concentration of PRN from the two CG-GS-PRN-LDH nanocomposite eye drops was higher than that of PRN-LDH during the first $90 \mathrm{~min}$. For the commercial product, PRN could be detected for only $2 \mathrm{~h}$, whereas

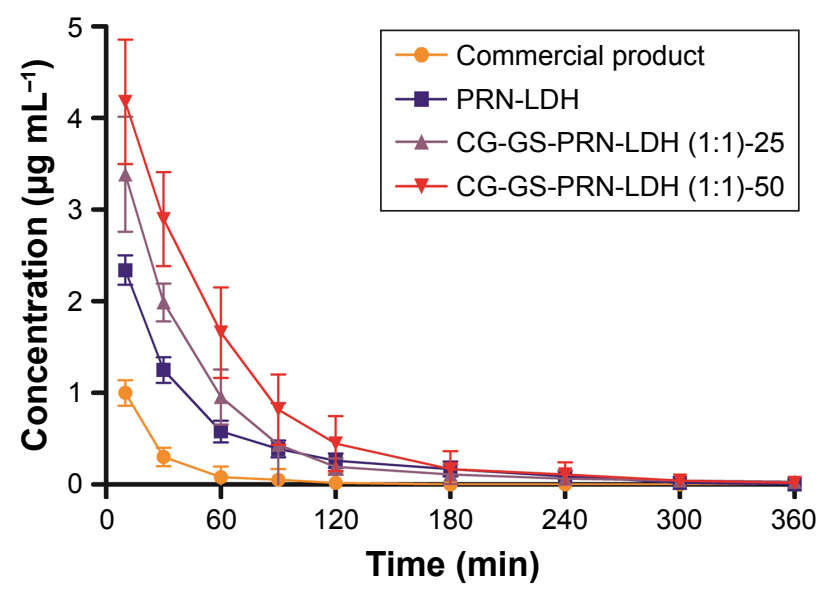

Figure 7 The concentration-time curves of PRN of different nanocomposite eye drops in rabbit tears (mean $\pm S D, n=6$ ).

Abbreviations: CG-GS, chitosan-glutathione-glycylsarcosine; LDH, layered double hydroxides; PRN, pirenoxine sodium. 
the drug remained detectable up to $6 \mathrm{~h}$ for CG-GS-PRN-LDH (1:1)-50 eye drops. In particular, the precorneal retention time was prolonged with the increasing amount of CG-GS in CGGS-PRN-LDH nanocomposites. In addition, the pharmacokinetic parameters of different formulations were calculated by PKsolver software (v 2.0). An ideal formulation should exhibit higher area under curve (AUC), peak tear concentration $\left(\mathrm{C}_{\max }\right)$ and mean residence time (MRT) for efficient and prolonged ocular drug exposure. The values of $\mathrm{AUC}_{0-6 \mathrm{~h}}, \mathrm{C}_{\max }$ and MRT for CG-GS-PRN-LDH nanocomposites with $25 \mathrm{mg}$ CG-GS were $161.68 \pm 41.66 \mu \mathrm{g} / \mathrm{mL} \bullet \mathrm{min}, 3.95 \pm 2.03 \mu \mathrm{g} / \mathrm{mL}$ and $36.44 \pm 17.20 \mathrm{~min}$, respectively. For CG-GS-PRNLDH nanocomposites with $50 \mathrm{mg}$ CG-GS, the values were $195.75 \pm 52.68 \mu \mathrm{g} / \mathrm{mL} \bullet \mathrm{min}, 5.12 \pm 1.58 \mu \mathrm{g} / \mathrm{mL}$ and $40.00 \pm 16.34 \mathrm{~min}$, respectively. In contrast with the data of commercial product and PRN-LDH eye drops which were published in our previous report, ${ }^{19}$ the CG-GS-PRN-LDH (1:1)-50 showed significantly higher $\mathrm{AUC}_{0-6 \mathrm{~h}}$ (6.7- and 1.8fold), $\mathrm{C}_{\max }$ (3.5- and 2.1-fold) and MRT (2.1- and 1.4-fold) $(P<0.05)$. When the amount of CG-GS was decreased, the pharmacokinetic parameters of $\mathrm{AUC}_{0-6 \mathrm{~h}}$ and MRT were statistically significantly different $(P<0.05)$ as compared to that of PRN-LDH eye drops, while a small, but noticeable (2.7-fold) increase in $\mathrm{C}_{\text {max }}$ was observed as compared to that of commercial product. These results revealed that CG-GS-PRN-LDH could prolong the retention time of PRN on the ocular surface and slow drug elimination. Apart from the ionic interaction between positively charged LDH and the negatively charged mucus layer of eye surface, the formation of disulfide bonds between the thiol groups in the CG-GS and the sticky protein in the mucus was also a key factor. ${ }^{50}$ In conclusion, the CG-GS-PRN-LDH nanocomposites with mucoadhesive effect offered a long-last action which could increase the drug permeability and thus were expected to increase the ocular bioavailability of topical drugs.

\section{Ex vivo fluorescence image of rabbit ocular tissues}

Figure 8 presents the fluorescence image of ocular tissues throughout the sclera, cornea, iris-ciliary and crystalline lens after topical administration. The fluorescence signals of FITCLDH eye drops were found to be primarily localized in cornea and sclera, suggesting that the precorneal retention could be enhanced in the presence of LDH compared with untreated ocular tissues. For CG-GS-FITC-LDH eye drops, the signals were stronger in all ocular tissues than that of FITC-LDH, especially in iris-ciliary and crystalline lens. This implied CG-GS could facilitate more FITC to arrive at the target ocular tissue of crystalline lens. Additionally, more fluorescence signals of CG-GS-FITC-LDH (1:1) were located in ocular tissues than those of CG-GS-FITC-LDH (1:0.5), but the fluorescence intensity of physical mixture was similar to that of CG-GS-FITC-LDH (1:0.5). The improved penetration confirmed that the higher amount of GS in CG-GS after hybridizing with LDH might enhance the ocular bioavailability by increasing the affinity to PepT-1 of corneal epithelium.

\section{In vivo tissue distribution study in rabbits}

Given that the higher content of GS exhibited better targeting and permeation ability from the cellular uptake and ex vivo

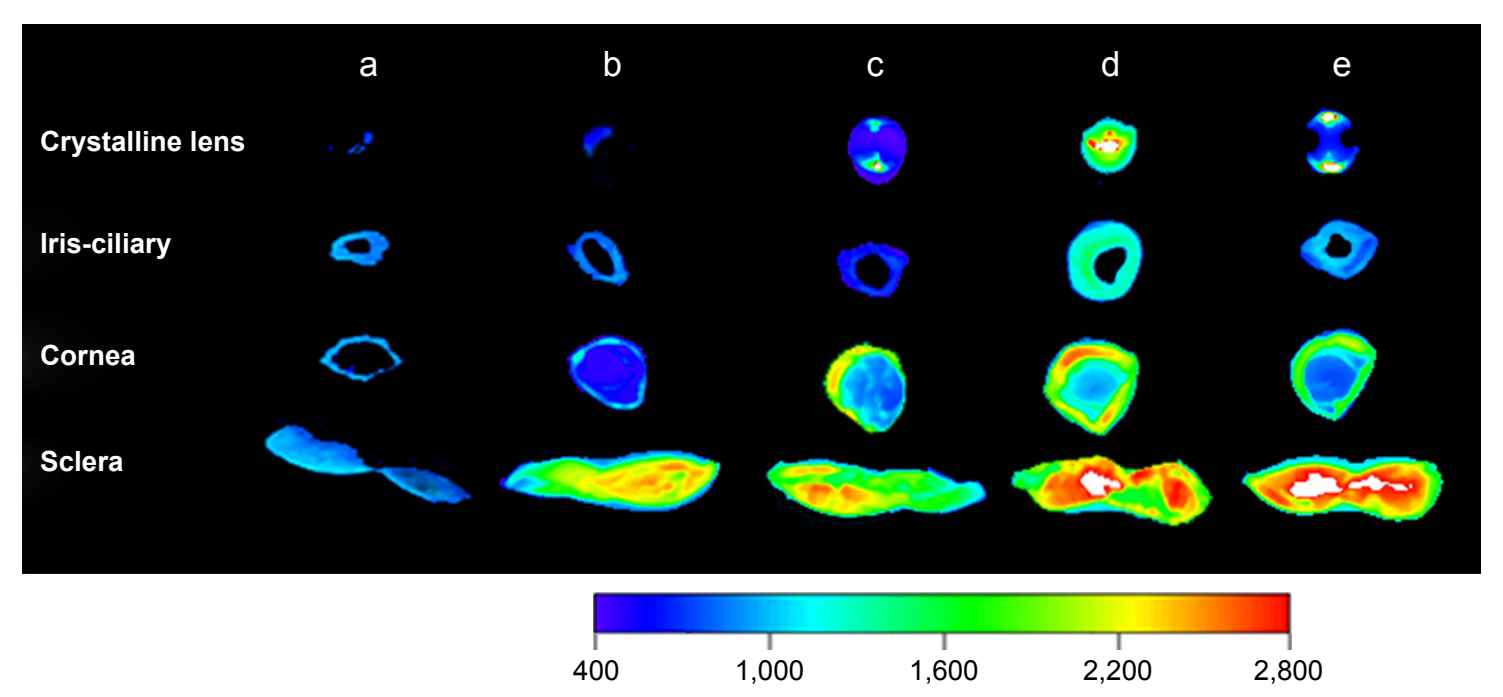

Figure 8 Ex vivo fluorescence imaging of rabbit ocular tissues from rabbit treated with FITC: blank (a), FITC-LDH (b), CG-GS-FITC-LDH (I:0.5)-50 (c), CG-GS-FITC-LDH (I:I)-50 (d) and physical mixture of CG-GS and FITC solution (e).

Abbreviations: CG-GS, chitosan-glutathione-glycylsarcosine; FITC, fluorescein isothiocyanate Isomer I; LDH, layered double hydroxides. 
fluorescence image results, CG-GS-PRN-LDH nanocomposite eye drops with $50 \mathrm{mg}$ of CG-GS (1:1) was chosen for tissue distribution study. Figure 9 illustrates the distribution of PRN in ocular tissues after topical administration of commercial product, PRN-LDH and CG-GS-PRN-LDH nanocomposite eye drops. Therein, the data of commercial product and PRNLDH were published in our previous report. ${ }^{19}$ For commercial eye drops, the concentration of PRN in ocular tissues decreased gradually over time except a small increase in aqueous humor and crystalline lens at $2 \mathrm{~h}$. The trend of drug concentration over
A
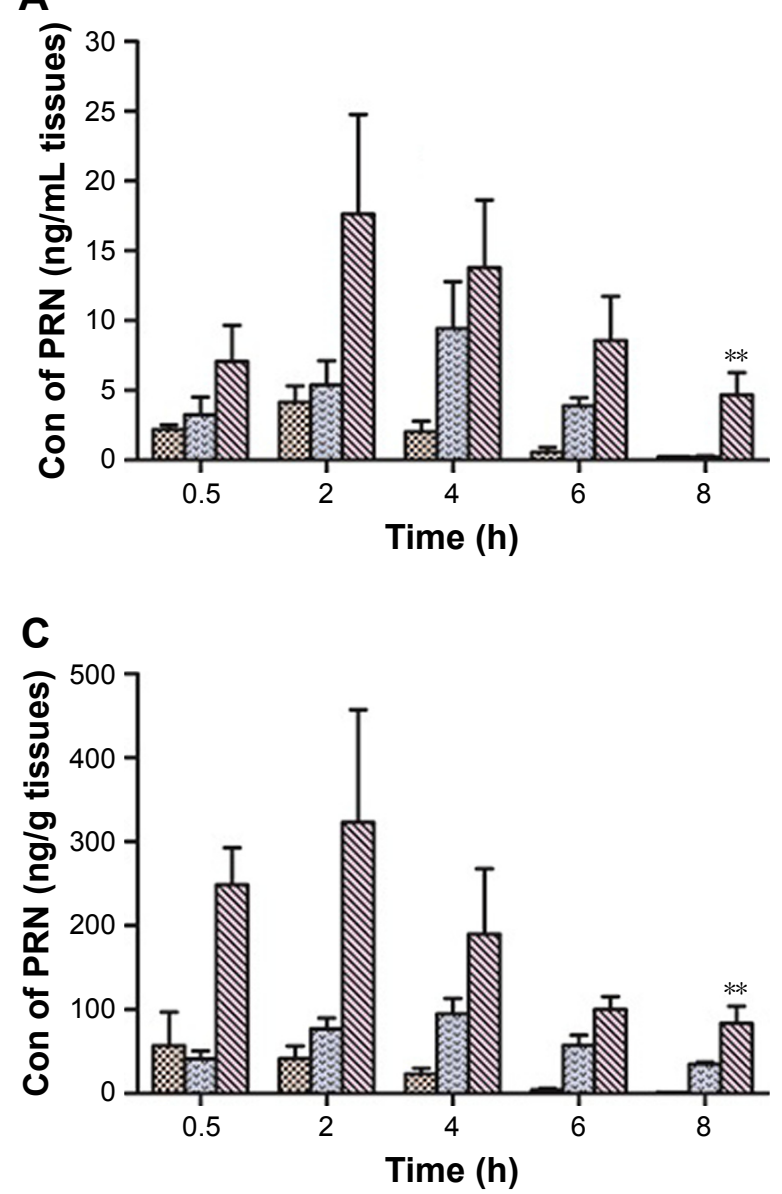

B
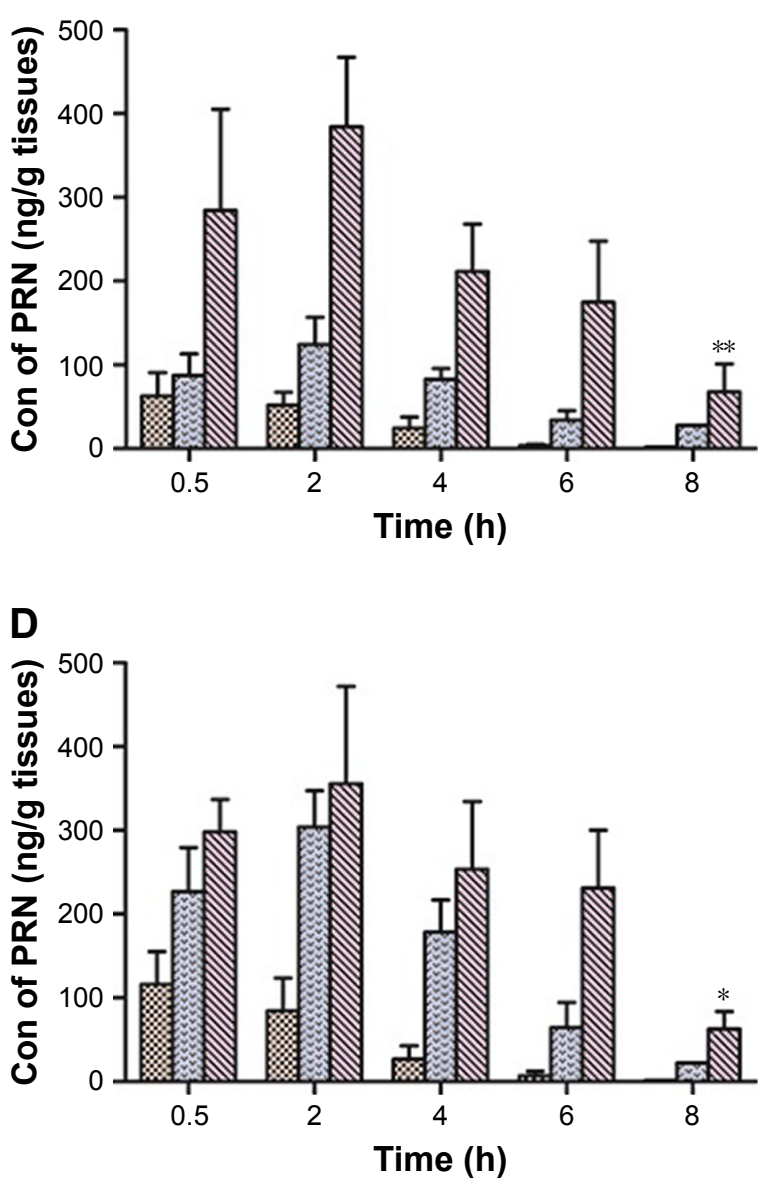

E

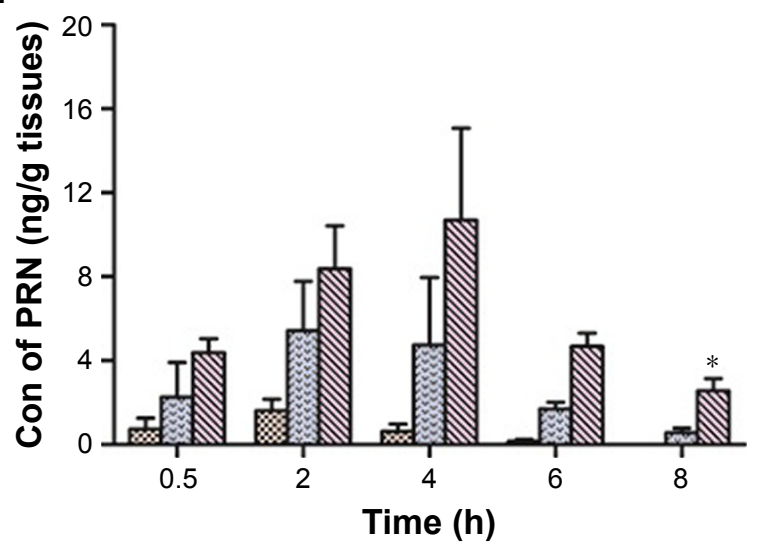

Commercial product

Figure 9 Concentrations of PRN in ocular tissues of aqueous humor $(\mathbf{A})$, cornea (B), iris-ciliary body (C), sclera (D)), and crystalline lens (E) at different time points (0.5, 2, 4,6 and $8 \mathrm{~h}$ ) after topical administration. (mean $\pm S D, n=3$ ). $* P<0.05$ versus commercial product group, $* * P<0.05$ versus $P R N-L D H$ group.

Abbreviations: Con, concentration; CG-GS, chitosan-glutathione-glycylsarcosine; LDH, layered double hydroxides; PRN, pirenoxine sodium. 
time was consistent with the results of previous study by Meng et al. ${ }^{26}$ Compared to the commercial product, drug concentration of CG-GS-PRN-LDH in aqueous humor and crystalline lens was significantly increased $(P<0.05)$. The highest drug concentration in aqueous humor was at $2 \mathrm{~h}$. In addition, the highest drug concentration in crystalline lens was at $4 \mathrm{~h}$, probably attributed to the increased drug concentration in aqueous humor and making the drug to enter the lens constantly. Statistical analysis showed that the concentration of PRN in all the ocular tissues was significantly different $(P<0.05)$ between CG-GS-PRN-LDH and commercial product after $8 \mathrm{~h}$. In the aqueous humor, cornea and iris-ciliary body, the concentration of PRN was significantly different $(P<0.05)$ between CGGS-PRN-LDH and PRN-LDH eye drops, possibly due to the active targeting and retention potential of CG-GS.

To further examine the in vivo efficacy, the values of $\mathrm{AUC}_{0-8 \mathrm{~h}}$ and MRT of CG-GS-PRN-LDH nanocomposite eye drops in different ocular tissues were calculated. The values of $\mathrm{AUC}_{0-8 \mathrm{~h}}$ in sclera, cornea, iris-ciliary body, aqueous humor and crystalline lens were 1,952.11 \pm 421.97 , $1,797.43 \pm 406.32,1,478.11 \pm 400.98,87.26 \pm 31.02$ and $52.35 \pm 10.58 \mathrm{ng} \cdot \mathrm{h} / \mathrm{mL}$, respectively. Meanwhile, the values of MRT were 4.71 $\pm 1.04,4.25 \pm 0.62,5.14 \pm 0.66,5.01 \pm 0.08$ and $5.19 \pm 1.65 \mathrm{~h}$, respectively. Compared with the data of commercial product and PRN-LDH eye drops group which were published in our previous report, ${ }^{19}$ the difference between CGGS-PRN-LDH and PRN-LDH eye drops group was significant in cornea, aqueous humor and crystalline lens $(P<0.05)$. Additionally, for aqueous humor samples, CG-GS-PRN-LDH eye drops exhibited 6.1-fold increase in $\mathrm{AUC}_{0-8 \mathrm{~h}}$ and 1.7-fold increase in MRT compared with commercial product. Meanwhile, compared with commercial product and PRN-LDH eye drops, for crystalline lens samples, CG-GS-PRN-LDH eye drops exhibited 10.5- and 2.1-fold increase in $\mathrm{AUC}_{0-8 \mathrm{~h}}$, respectively, proposing that the functional intercalated nanocomposites could be promising candidates for ocular disease. The multifunction was related to the prolonged retention at the preocular surface and the enhanced corneal permeability with these nanocomposites. These results demonstrated that the nanocomposites based on thiolated polymers of CG-GS and inorganic carrier of LDH could really deliver the model drug of PRN into eye tissues, resulting in high distribution of PRN into the target tissue of crystalline lens, which was in accordance with the results of the ex vivo fluorescence image of rabbit ocular tissues. Furthermore, the results of ex vivo fluorescence image and the in vivo tissue distribution study in rabbits also revealed that the amount of fluorescent dye or model drug in the sclera was quite higher than that of other ocular tissues, suggesting that these organic-intercalated LDH nanocomposites might be promising carriers for topical drug delivery to the posterior segment of the eye..$^{51}$

\section{Evaluation of eye irritancy}

Given that CG-GS-LDH nanocomposites are novel drug carriers intended for use as an ocular drug delivery system, it is important to evaluate their tolerability in living organism. The value of OII obtained from different DS of CG-GS in CG-GS-PRN-LDH nanocomposite eye drops was null, thus the nanocomposites could be classified as non-irritant. Histopathological analysis by microscopy was used to assess cell structure and tissue integrity to detect irritation. Representative micrographs of three tissues (cornea, iris and conjunctiva) treated with different preparations are shown in Figure S7. There were no toxicological features observed in the three tissues including the epithelium and the stroma at 7 days after ocular treatment with CG-GS-PRN-LDH nanocomposite eye drops as compared with normal saline treatment or blank as controls, suggesting that the formulations caused no significant ocular irritation. All these results further confirm that CG-GS-PRN-LDH nanocomposites are biocompatible with excellent ocular tolerance, which makes them a very promising option for ocular drug delivery.

\section{Conclusion}

In this study, functional intercalated nanocomposites based on CG-GS and LDH were developed for transporter-targeted ocular drug delivery. Dipeptide GS may be a potential molecule targeting moiety, which could efficiently guide CG-GS-LDH nanocomposites to PepT-1 expressed on the cornea of eyes. In addition, CG-GS-LDH nanocomposites exhibited enhanced bioadhesion, sustained release, better corneal permeability and biocompatibility in vivo. The results of this work also indicated that CG-GS-LDH nanocomposites could be a promising strategy for topical ocular drug delivery and provide a potential tool for the treatment of mid-posterior segment diseases.

\section{Acknowledgment}

This work was supported by the National Natural Science Foundation of China (No 81373362) and the fundamental research funds for the central universities of China (no PT2014YX0054).

\section{Disclosure}

The authors report no conflicts of interest in this work.

\section{References}

1. Barar J, Aghanejad A, Fathi M, Omidi Y. Advanced drug delivery and targeting technologies for the ocular diseases. BioImpacts. 2016; $6(1): 49-67$. 
2. Kawashima T, Nagai N, Kaji H, et al. A scalable controlled-release device for transscleral drug delivery to the retina. Biomaterials. 2011; 32(7):1950-1956.

3. Shmueli RB, Ohnaka M, Miki A, et al. Long-term suppression of ocular neovascularization by intraocular injection of biodegradable polymeric particles containing a serpin-derived peptide. Biomaterials. 2013;34(30):7544-7551.

4. Lai JY, Hsieh AC. A gelatin-g-poly(N-isopropylacrylamide) biodegradable in situ gelling delivery system for the intracameral administration of pilocarpine. Biomaterials. 2012;33(7):2372-2387.

5. Lai PX, Chen CW, Wei SC, et al. Ultrastrong trapping of VEGF by graphene oxide: anti-angiogenesis application. Biomaterials. 2016; 109(Suppl C):12-22.

6. Agarwal P, Rupenthal ID. Modern approaches to the ocular delivery of cyclosporine A. Drug Disco Today. 2016;21(6):977-988.

7. Cholkar K, Patel A, Vadlapudi AD, Mitra AK. Novel nanomicellar formulation approaches for anterior and posterior segment ocular drug delivery. Recent Pat Nanomed. 2012;2(2):82-95.

8. Mandal A, Bisht R, Rupenthal ID, Mitra AK. Polymeric micelles for ocular drug delivery: from structural frameworks to recent preclinical studies. J Control Release. 2017;248:96-116.

9. Battaglia L, Serpe L, Foglietta F, et al. Application of lipid nanoparticles to ocular drug delivery. Expert Opin Drug Deliv. 2016;13(12): 1743-1757

10. Gaudana R, Ananthula HK, Parenky A, Mitra AK. Ocular drug delivery. AAPS J. 2010;12(3):348-360.

11. Ban J, Zhang Y, Huang X, et al. Corneal permeation properties of a charged lipid nanoparticle carrier containing dexamethasone. Int $J$ Nanomedicine. 2017;12:1329-1339.

12. Bonengel S, Bernkop-Schnurch A. Thiomers - from bench to market. J Control Release. 2014;195:120-129.

13. Yavuz B, Kompella UB. Ocular drug delivery. In: Handbook of Experimental Pharmacology. 2016.

14. Majumdar S, Nashed YE, Patel K, et al. Dipeptide monoester ganciclovir prodrugs for treating HSV-1-induced corneal epithelial and stromal keratitis: in vitro and in vivo evaluations. J Ocul Pharmacol Ther. 2005; 21:463-474

15. Cao F, Wang Y, Ping Q, Liao Z. Zn-Al-NO(3)-layered double hydroxides with intercalated diclofenac for ocular delivery. Int J Pharm. 2011;404(1-2):250-256.

16. Qin Z, Zhang J, Chi H, Cao F. Organic-inorganic hybrid nanocomposites based on chitosan derivatives and layered double hydroxides with intercalated phacolysin as ocular delivery system. J Nanopart Res. 2015; 17(12):468.

17. Sun J, Lei Y, Dai Z, et al. Sustained release of brimonidine from a new composite drug delivery system for treatment of glaucoma. ACS Appl Mater Interfaces. 2017;9(9):7990-7999.

18. Mandal A, Agrahari V, Khurana V, Pal D, Mitra AK. Transporter effects on cell permeability in drug delivery. Expert Opin Drug Deliv. 2017; 14(3):385-401.

19. Xu T, Zhang J, Chi H, Cao F. Multifunctional properties of organicinorganic hybrid nanocomposites based on chitosan derivatives and layered double hydroxides for ocular drug delivery. Acta Biomater. 2016; 36:152-163.

20. Chi H, Gu Y, Xu T, Cao F. Multifunctional organic-inorganic hybrid nanoparticles and nanosheets based on chitosan derivative and layered double hydroxide: cellular uptake mechanism and application for topical ocular drug delivery. Int J Nanomedicine. 2017;12:1607-1620.

21. Leroux F, Besse JP. Polymer interleaved layered double hydroxide: a new emerging class of nanocomposites. Chem Mater. 2001;13: 3507-3515.

22. Zheng YL, Chen YH. Preparation of polypropylene/Mg-Al layered double hydroxides nanocomposites through wet pan-milling: formation of a second-staging structure in LDHs intercalates. RSC $A d v .2017$; 7(3):1520-1530.

23. Tronto J, Bordonal AC, Naal Z, Valim JB. Conducting polymers/ layered double hydroxides intercalated nanocomposites. In: Materials Science-Advanced Topics. 2013.
24. Peterson LW, Rabanal MS, Krylov IS, Serpi M, Kashemirov BA, McKenna CE. Serine side chain-linked peptidomimetic conjugates of cyclic HPMPC and HPMPA: synthesis and interaction with hPEPT1. Mol Pharm. 2010;7(6):2349-2361.

25. Coon SD, Rajendran VM, Schwartz JH, Singh SK. Glucose-dependent insulinotropic polypeptide-mediated signaling pathways enhance apical PepT1 expression in intestinal epithelial cells. Am J Physiol Gastrointest Liver Physiol. 2015;308(1):G56-G62.

26. Otter M, Oswald S, Siegmund W, Keiser M. Effects of frequently used pharmaceutical excipients on the organic cation transporters 1-3 and peptide transporters $1 / 2$ stably expressed in MDCKII cells. Eur $J$ Pharmaceutics Biopharm. 2017;112:187-195.

27. Choi JS, Nam K, Park J-Y, Kim J-B, Lee J-K, Park J-S. Enhanced transfection efficiency of PAMAM dendrimer by surface modification with 1-arginine. J Control Release. 2004;99(3):445-456.

28. Jin XF, Xu Y, Shen J, Ping QN, Su ZG, You WL. Chitosan-glutathione conjugate-coated poly(butyl cyanoacrylate) nanoparticles: promising carriers for oral thymopentin delivery. Carbohydr Polym. 2011;86(1): 51-57.

29. Shah SU, Martinho N, Socha M, Pinto Reis C, Gibaud S. Synthesis and characterization of S-nitrosoglutathione-oligosaccharidechitosan as a nitric oxide donor. Expert Opin Drug Deliv. 2015;12(8): 1209-1223.

30. Kongsong M, Songsurang K, Sangvanich P, Siralertmukul K, Muangsin N. Design, synthesis, fabrication and in vitro evalution of mucoadhesive 5-amino-2-mercaptobenzimidazole chitosan as low water soluble drug carriers. Eur J Pharm Biopharm. 2014;88(3):986-997.

31. Meng XM, Zhao PQ, Zhang RW, Chen CZ. Catalin ophthalmic solution distribution in various tissues of rabbit eye at different time. Ophthalmol CHN. 1999;8(2):120-122.

32. Sánchez-López E, Egea MA, Cano A, et al. PEGylated PLGA nanospheres optimized by design of experiments for ocular administration of dexibuprofen - in vitro, ex vivo and in vivo characterization. Colloids Surf B Biointerfaces. 2016;145:241-250.

33. Wilhelmus KR. The Draize eye test. Surv Ophthalmol. 2001;45(6): 493-515.

34. Abrego G, Alvarado H, Souto EB, et al. Biopharmaceutical profile of pranoprofen-loaded PLGA nanoparticles containing hydrogels for ocular administration. Eur J Pharm Biopharm. 2015;95(Part B): 261-270.

35. Tan XF, Liu YG, Gu YL, et al. Biochar pyrolyzed from MgAl-layered double hydroxides pre-coated ramie biomass (Boehmeria nivea (L.) Gaud.): characterization and application for crystal violet removal. J Environ Manage. 2016;184(Part 1):85-93.

36. Cunha VR, Guilherme VA, de Paula E, et al. Delivery system for mefenamic acid based on the nanocarrier layered double hydroxide: physicochemical characterization and evaluation of anti-inflammatory and antinociceptive potential. Mater Sci Eng C Mater Biol Appl. 2016; 58:629-638

37. Leroux F, Aranda P, Besse JP, Ruiz-Hitzky E. Intercalation of poly(ethylene oxide) derivatives into layered double hydroxides. Eur J Inorg Chem. 2003;2003(6):1242-1251.

38. Nakayama H, Wada N, Tsuhako M. Intercalation of amino acids and peptides into $\mathrm{Mg}-\mathrm{Al}$ layered double hydroxide by reconstruction method. Int J Pharm. 2004;269(2):469-478.

39. Senapati S, Thakur R, Verma SP, et al. Layered double hydroxides as effective carrier for anticancer drugs and tailoring of release rate through interlayer anions. J Control Release. 2016;224:186-198.

40. Felix C, Yaroshchuk A, Pasupathi S, et al. Electrophoresis and stability of nano-colloids: history, theory and experimental examples. Adv Colloid Interface Sci. 2014;211:77-92.

41. Mondal S, Dasgupta S, Maji K. MgAl-layered double hydroxide nanoparticles for controlled release of salicylate. Mater Sci Eng C Mater Biol Appl. 2016;68:557-564.

42. Zhu R, Wang Q, Zhu Y, et al. pH sensitive nano layered double hydroxides reduce the hematotoxicity and enhance the anticancer efficacy of etoposide on non-small cell lung cancer. Acta Biomater. 2016; 29:320-332. 
43. Jian HJ, Wu RS, Lin TY, et al. Super-cationic carbon quantum dots synthesized from spermidine as an eye drop formulation for topical treatment of bacterial keratitis. ACS Nano. 2017;11(7):6703-6716.

44. Ma K, Hu Y, Smith DE. Peptide transporter 1 is responsible for intestinal uptake of the dipeptide glycylsarcosine: studies in everted jejunal rings from wild-type and Pept1 null mice. J Pharm Sci. 2011;100(2): 767-774.

45. Oh JM, Choi SJ, Lee GE, Kim JE, Choy JH. Inorganic metal hydroxide nanoparticles for targeted cellular uptake through clathrin-mediated endocytosis. Chem Asian J. 2009;4(1):67-73.

46. Barar J, Javadzadeh AR, Omidi Y. Ocular novel drug delivery: impacts of membranes and barriers. Expert Opin Drug Deliv. 2008; 5(5):567-581.

47. Otter M, Oswald S, Siegmund W, Keiser M. Effects of frequently used pharmaceutical excipients on the organic cation transporters 1-3 and peptide transporters 1/2 stably expressed in MDCKII cells. Eur J Pharm Biopharm. 2017;112:187-195.
48. Dai T, Li N, Zhang L, Zhang Y, Liu Q. A new target ligand Ser-Glu for PEPT1-overexpressing cancer imaging. Int J Nanomedicine. 2016; 11:203-212.

49. Zeng W, Li Q, Wan T, et al. Hyaluronic acid-coated niosomes facilitate tacrolimus ocular delivery: mucoadhesion, precorneal retention, aqueous humor pharmacokinetics, and transcorneal permeability. Colloids Surf B Biointerfaces. 2016;141:28-35.

50. Liu D, Li J, Pan H, et al. Potential advantages of a novel chitosan$\mathrm{N}$-acetylcysteine surface modified nanostructured lipid carrier on the performance of ophthalmic delivery of curcumin. Sci Rep. 2016;6: 28796.

51. Cholkar K, Gunda S, Earla R, Pal D, Mitra AK. Nanomicellar topical aqueous drop formulation of rapamycin for back-of-the-eye delivery. AAPS PharmSciTech. 2015;16(3):610-622. 


\section{Supplementary materials}

Table SI Draize's scale of weighted scores for grading the severity of ocular lesions

Assessment

Score

Cornea

A. Opacity - degree of density (most dense area taken for reading)

No ulceration or opacity

Scattered or diffuse area; details of iris clearly visible

Easily discernible translucent areas; details of iris slightly obscured

Opalescent areas; no details of iris visible, size of pupil barely discernible

Opaque; iris invisible

B. Area of cornea involved

None

One-quarter (or less) but not zero

Greater than one-quarter, less than one-half

Greater than one-half, less than three-quarters

Greater than three-quarters, up to whole area

0

I

2

3

4

0

I

2

3

4

Score $=A \times B \times 5($ range, 0 to 80$)$

Iris

A. Values

Normal

Folds above normal, congestion, swelling and/or circumcorneal injection; iris still reacting to light (sluggish reaction is positive)

No reaction to light, hemorrhage and/or gross destruction

Score $=\mathrm{A} \times 5$ (range, 0 to 10$)$

\section{Conjunctivae}

A. Redness of palpebral conjunctivae

Normal

Vessels definitely injected above normal

More diffuse, deeper crimson red; individual vessels not easily discernible

Diffuse beefy red

B. Chemosis

Normal

Any swelling above normal (includes nictitating membrane)

Obvious swelling with partial eversion of the lid

Swelling with lids about half closed

Swelling with lids about half closed to completely closed

Discharge

Normal

Any amount different from normal

Discharge with moistening of the lids and hair just adjacent to the lids

Discharge with moistening of the lids and considerable area around the eye

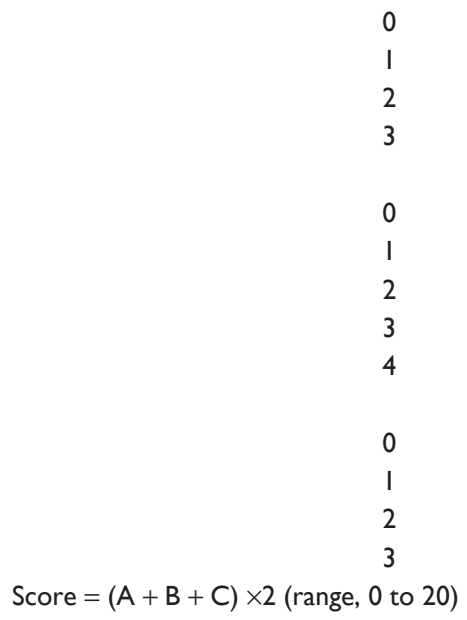

0

Total score=Sum of all scores obtained for the cornea, iris and conjunctivae

Table S2 Classification of products according to the Draize ocular irritation index (OII)

\begin{tabular}{lc}
\hline Average score & Classification \\
\hline 0 & Non-irritant \\
$0-15$ & Slightly irritant \\
$>15-30$ & Moderately irritant \\
$>30-50$ & Irritant \\
$>50$ & Very irritant \\
\hline
\end{tabular}




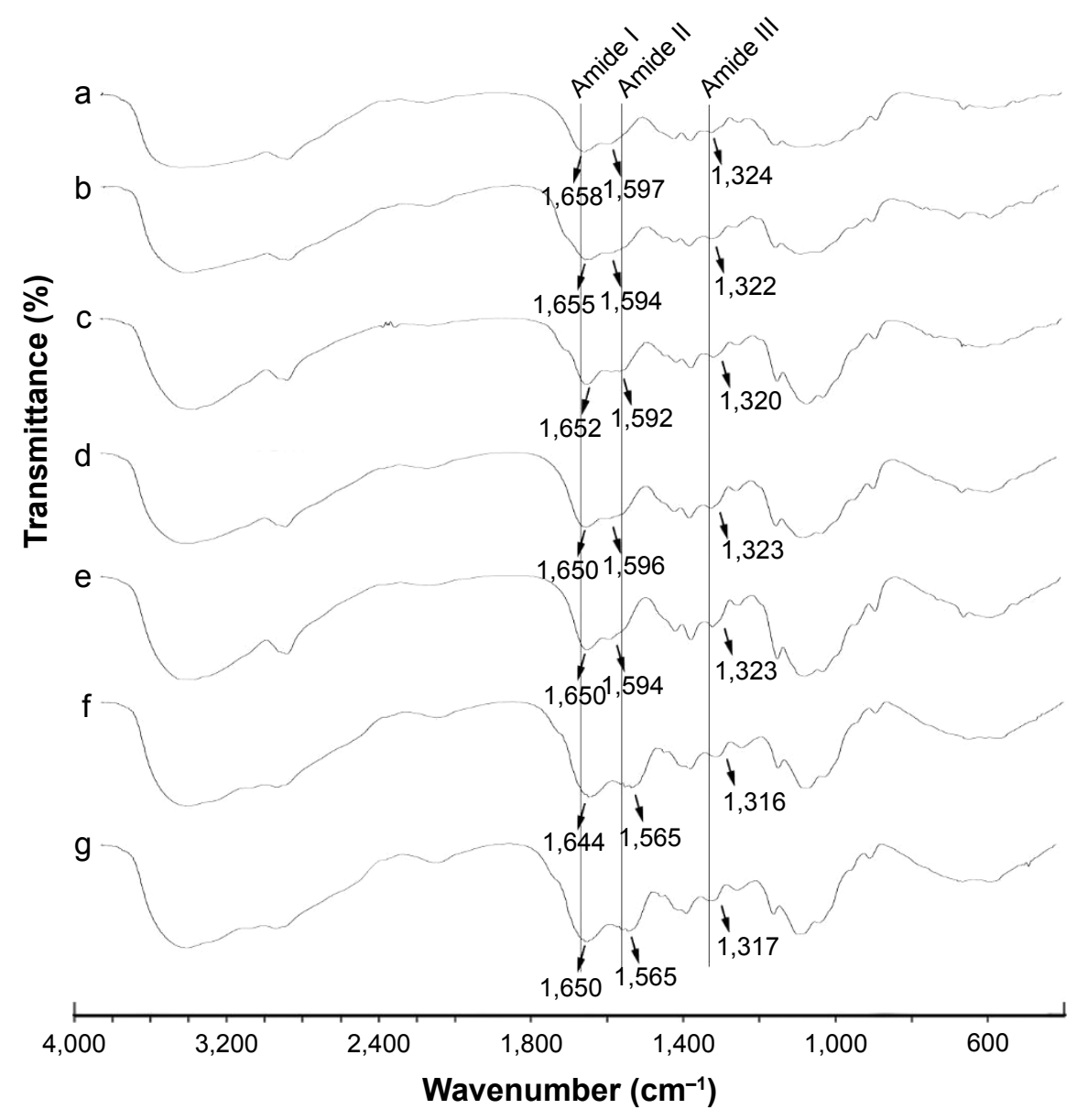

Figure SI IR spectra of CTS (a), CTS-Fmoc-GS (I:0.5) (b), CTS-Fmoc-GS (I:I) (c), CTS-GS (I:0.5) (d), CTS-GS (I:I) (e), CG-GS (I:0.5) (f) and CG-GS (I:I) (g). Abbreviations: CTS, chitosan; CG-GS, chitosan-glutathione-glycylsarcosine; IR, infrared.
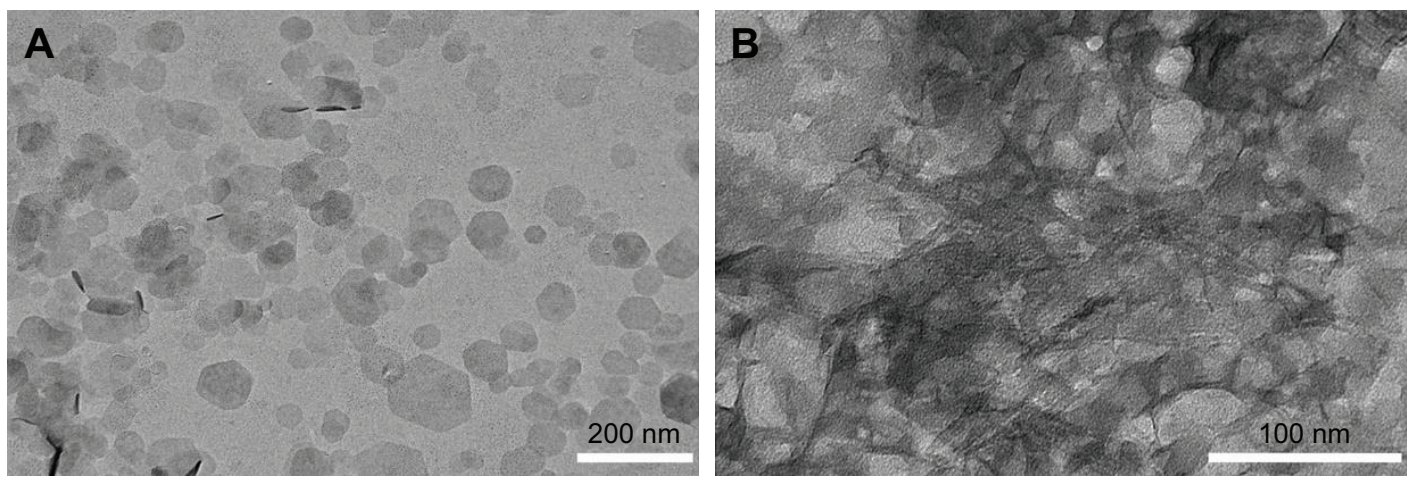

Figure S2 TEM micrographs of Mg-Al-NO - -LDH (A) and CG-GS-PRN-LDH (B).

Abbreviations: CG-GS, chitosan-glutathione-glycylsarcosine; LDH, layered double hydroxides; PRN, pirenoxine sodium; TEM, transmission electron micrography. 


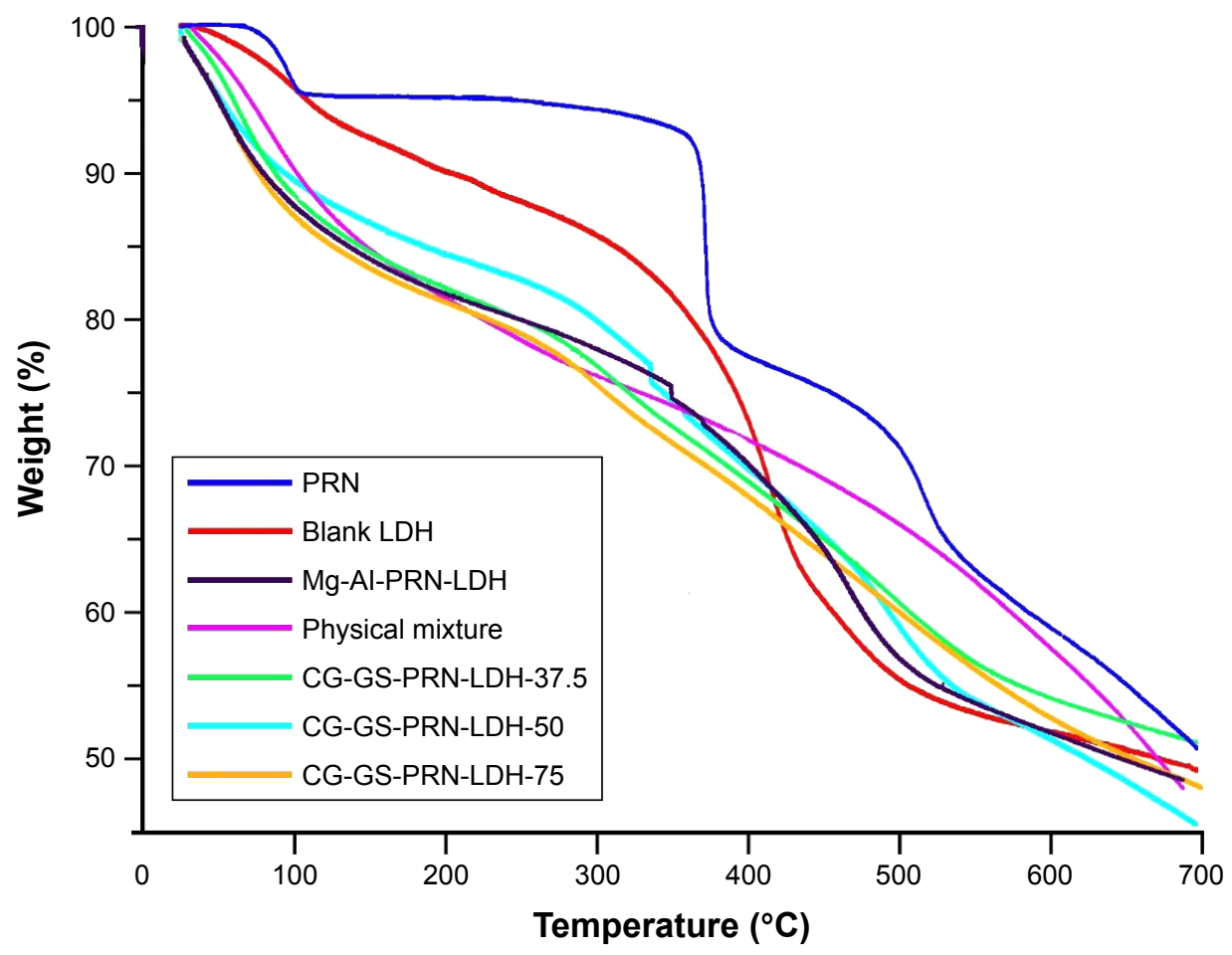

Figure S3 Thermogravimetric analyses of PRN, blank LDH, Mg-AI-PRN-LDH nanoparticles, different amounts of CG-GS for CG-GS-PRN-LDH nanocomposites and the physical mixture of CG-GS and PRN-LDH.

Abbreviations: CG-GS, chitosan-glutathione-glycylsarcosine; LDH, layered double hydroxides; PRN, pirenoxine sodium.

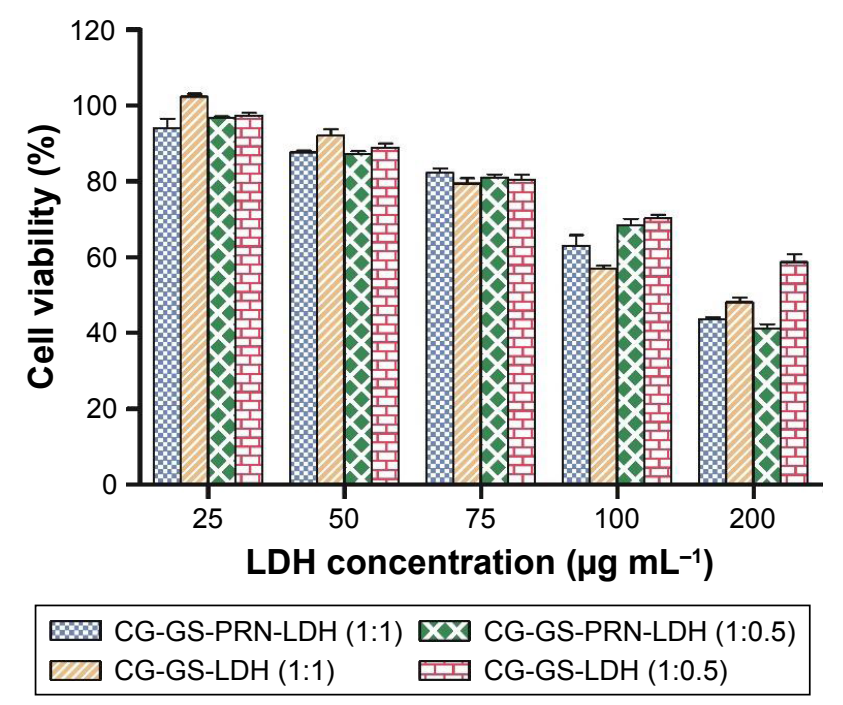

Figure S4 HCEpiC cell viability of CG-GS-PRN-LDH (I:I), CG-GS-LDH (I:I), CGGS-PRN-LDH (I:0.5) and CG-GS-LDH (I:0.5) nanocomposites at different LDH concentrations. Data represent the mean and SD of triplicate experiments.

Abbreviations: CG-GS, chitosan-glutathione-glycylsarcosine; HCEpiC, human corneal epithelial primary cells; LDH, layered double hydroxides; PRN, pirenoxine sodium.

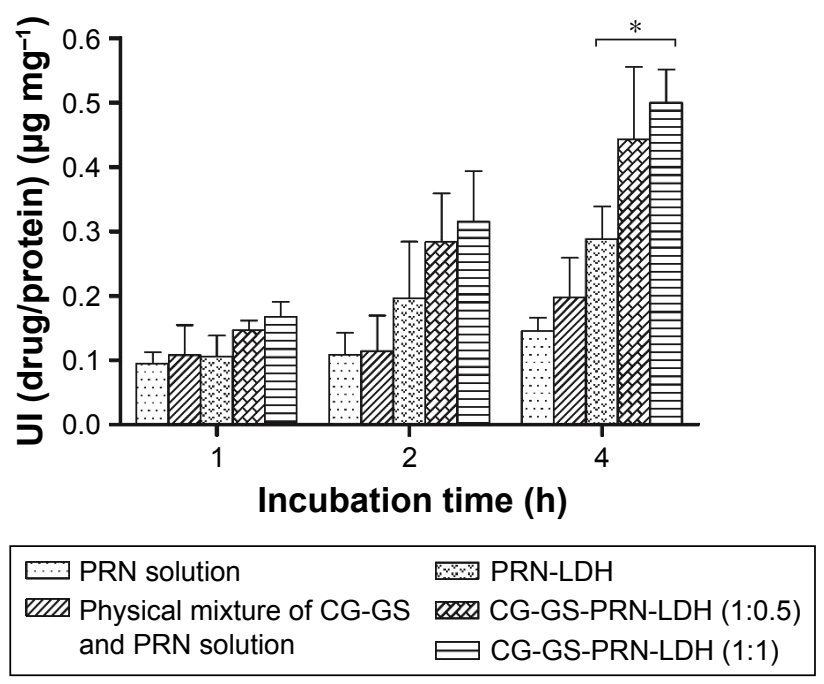

Figure S5 In vitro cellular uptake of CG-GS-PRN-LDH (I:I) nanocomposites, CG-GS-PRN-LDH (I:0.5) nanocomposites, PRN-LDH nanoparticles, physical mixture of CG-GS and PRN solution $(0.00038 \%[\mathrm{w} / \mathrm{v}])$ and PRN solution at different time points (mean $\pm S D, n=3$ ). $* P<0.05$ vs $P R N-L D H$. The bar shown is $25 \mu \mathrm{m}$.

Abbreviations: CG-GS, chitosan-glutathione-glycylsarcosine; LDH, layered double hydroxides; PRN, pirenoxine sodium; UI, uptake index. 


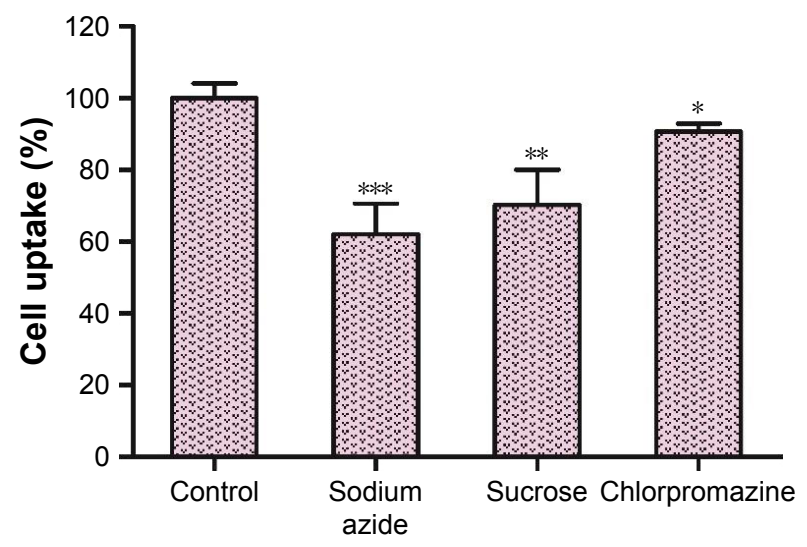

Figure $\mathbf{S 6}$ The effects of endocytic inhibitors on cellular uptake of CG-GS-FITC-LDH nanocomposites (mean \pm SD, $n=3$ ). $* P<0.05, * * P<0.01, * * * P<0.00$ l vs control group. Abbreviations: CG-GS, chitosan-glutathione-glycylsarcosine; FITC, fluorescein isothiocyanate Isomer I; LDH, layered double hydroxides.
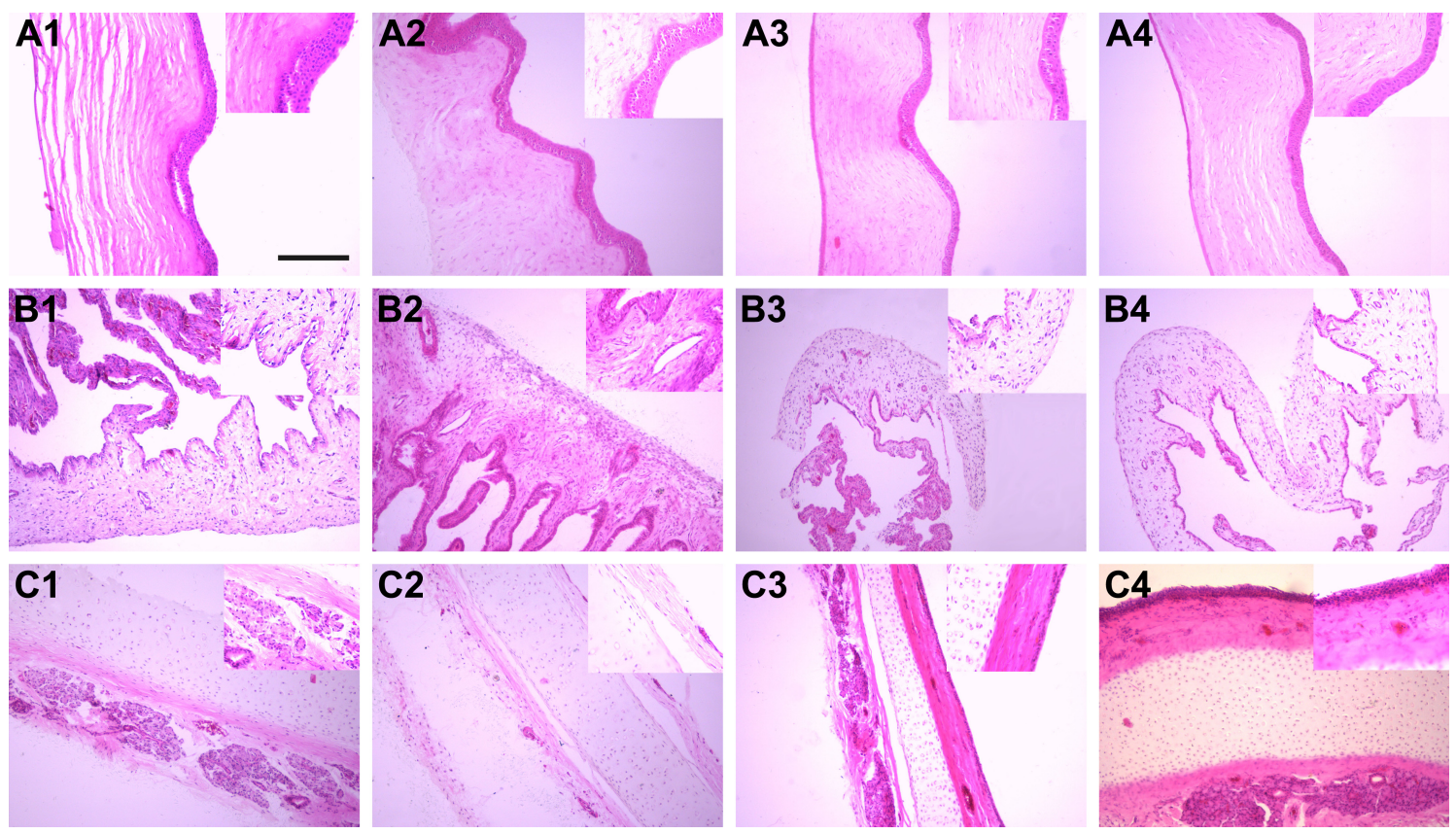

Figure S7 Histopathology microscopy of cornea (A), iris (B), and conjunctiva (C) after treating with different formulations for 7 days: (I) blank; (2) normal saline; (3) CGGS-PRN-LDH (I:0.5); (4) CG-GS-PRN-LDH (I:I), $\mathrm{n}=3$. The bar shown is $50 \mu \mathrm{m}$. The insert shows the representative images that appears in each figure part. (Hematoxylineosin stain; original magnifications $\times 100$; insert $\times 400)$.

Abbreviations: CG-GS, chitosan-glutathione-glycylsarcosine; LDH, layered double hydroxides; PRN, pirenoxine sodium.

International Journal of Nanomedicine

Dovepress

\section{Publish your work in this journal}

The International Journal of Nanomedicine is an international, peerreviewed journal focusing on the application of nanotechnology in diagnostics, therapeutics, and drug delivery systems throughou the biomedical field. This journal is indexed on PubMed Central, MedLine, CAS, SciSearch $\AA$, Current Contents ${ }^{\circledR} /$ Clinical Medicine,
Journal Citation Reports/Science Edition, EMBase, Scopus and the Elsevier Bibliographic databases. The manuscript management system is completely online and includes a very quick and fair peer-review system, which is all easy to use. Visit http://www.dovepress.com/ testimonials.php to read real quotes from published authors. 